\title{
SÍNTESIS GEOLÓGICA Y PALEONTOLÓGICA DE LA ISLA DE FUERTEVENTURA: ITINERARIOS CIENTÍFICOS DE LAS XIV JORNADAS DE PALEONTOLOGÍA
}

\author{
Carolina CASTILLO', Ramón CASILLAS', Agustina AHIJADO², \\ Margarita GUTIÉRREZ² y Esther MARTÍN GONZÁLEZ' \\ ' Departamento de Biología Animal. Facultad de Biología. Universidad de La Laguna. 38206. La Laguna. \\ Tenerife. E-mail: ccruiz@ull.es \\ - Departamento de Edafologíal y Geología. Facultad de Biología. Universidad de La Laguna. 38206. Lal \\ Laguna, Tenerife.
}

\begin{abstract}
Castillo, C., Casillas, R., Ahijado, A.. Gutiérrez, M. y Martín González, E. 2001. Síntesis geológicá y paleontológica de la isla de Fuerteventura: itinerarios científicos de las XIV Jornadas de Paleontología. [Geological and palaeontological synthesis of the Fuerteventura Island: Scientific itinerary of the XIV Palaeontological Congress.| Revista Española de Paleontología, n. ${ }^{\circ}$ extraordinario. 59-80. ISSN 021.3-6937.
\end{abstract}

\begin{abstract}
Fuerteventura is the oldest of the Canary Islands and thus shows the most important canarian fossil record. This include different types of deposits and fossils distributed from Jurasic times to present. The geological features of the island are also notable for their variety of rocks and outcrops that let to follow the birth and later growth of and oceanic island. Fuerteventura is an ideal place for the settlement of scientific routes such as those developed in the XIV Congress of Palaeontology. The aim of these routes is the observation of materials of different formations present on the island. From its Pliocene and Upper Pleistocene raised-beaches to dunes of Holocene age. Other types of palaeontological site visited were lava-tunnels, which show important palaeontological information.
\end{abstract}

Keywords: Geology, palaeontology, scientific itinerary, Fuerteventura, Canary Islands.

\section{RESUMEN}

La isla de Fuerteventura es una de las más antiguas del Canarias, y en ella se encuentra el registro paleontológico más importante del Archipiélago. Este incluye diferentes tipos de yacimientos y fósiles distribuidos en el tiempo de forma puntual desde el Jurásico hasta la actualidad. También los rasgos geológicos de la isla son muy destacables por la diversidad de tipos de rocas (algunas mu poco comunes como las carbonatitas), y por la existencia de afloramientos que permiten seguir el nacimiento y posterior crecimiento de una isla oceánica. Estas razones, entre otras, hacen de Fuerteventura un lugar ideal para el establecimiento de itinerarios científicos como los desarrollados en las XIV Jornadas de Paleontología. El objetivo de estos itinerarios ha sido la observación de los materiales de las diferentes formaciones de la isla, desde las playas levantadas del Plioceno y Pleistoceno superior, hasta las formaciones dunares del Holoceno. Otros tipos de yacimientos paleontológicos visitados han sido los tubos volcánicos, los cuales ofrecen una importante información paleontológica.

Palabras clave: Geología, paleontología, itinerarios científicos, Fuerteventura, Islas Canarias.

\section{INTRODUCCIÓN}

Fuerteventura, con una superficie de $1.662 \mathrm{~km}^{2}$, incluida la isla de Lobos, es la segunda isla en extensión del Archipiélago Canario. Frente a esta notable extensión, su cota máxima no alcanza los $1.0(0)$ metros (Pico de la Zarza, $8(07 \mathrm{~m})$, siendo exigua la superficie situada por encima de los 6()() $\mathrm{m}$.

Desde el punto de vista geológico, en la isla se pueden distinguir cuatro grandes formaciones rocosas (Fig. 1) (Fúster et al., 1968a; Ancochea et al., 1993): el Complejo Basal, que aflora principalmente en el sector occidental de la isla, en el Macizo de Betancuria; los restos de los edificios volcánicos subaéreos del primer ciclo del vulcanismo de edad miocena; los edificios volcánicos subaéreos del segundo ciclo de vulcanismo de edad pliocuaternaria (Series II, III y IV), y los sedimentos pliocuaternarios. 


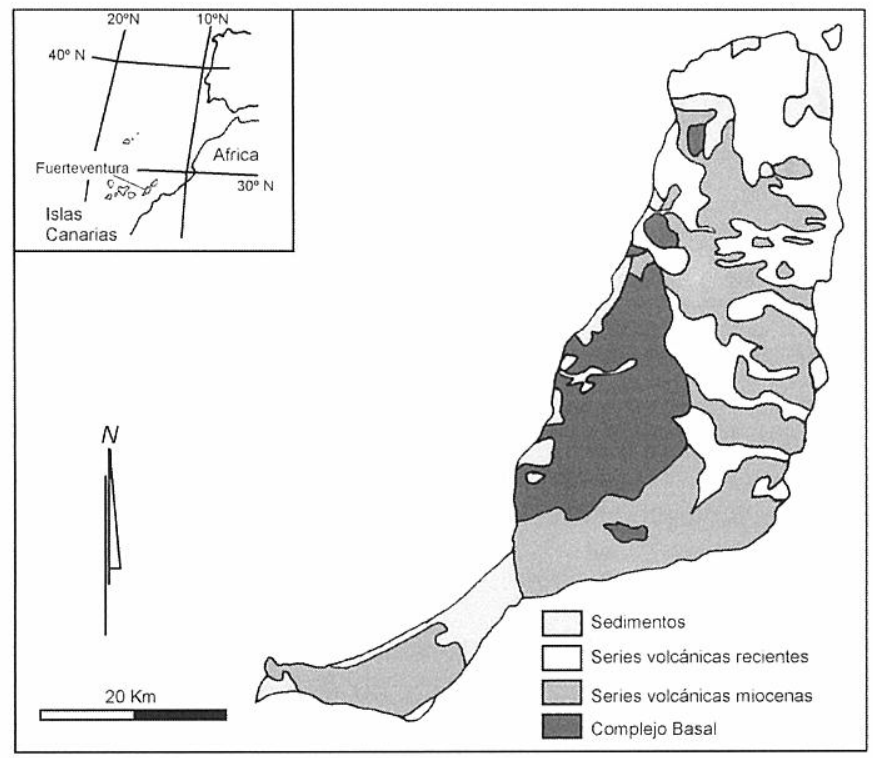

Figura 1. Mapa geológico de la isla de Fuerteventura (Ancochea et al., 1993).

Geological map of Fuerteventura Island (Ancochea et al., 1993).

El registro paleontológico de la Isla, aunque dilatado en el tiempo, es puntual. Han sido citadas, al menos, 42 localidades fosilíferas pertenecientes al final del Mesozoico, Paleógeno, Neógeno y Cuaternario, siendo este último periodo el mejor representado, tanto en extensión como en número y tipos de yacimientos. En otro orden de cosas, diez de estas localidades fueron incluidas en los fundamentos de la declaración de diferentes categorías de espacios naturales protegidos, como es el caso de los Monumentos Naturales de Ajuy y Cuchillos de Vigán (Castillo et al., 1999).

Las clases de fósiles que se han identificado en la Isla son muy variadas, y pertenecen tanto a huellas como a restos corporales de macro y microfósiles de Flora y Fauna. Estos fósiles se han encontrado en diferentes formaciones sedimentarias, como los sedimentos marinos profundos, someros y costeros; los depósitos dunares, sedimentos de barranco, tubos volcánicos y cavidades del malpaís. Los tubos volcánicos, a pesar de su corta vida (unos 500.000 años como máximo), constituyen importantes reservorios de información paleontológica de las asociaciones faunísticas del medio terrestre.

Las características antes mencionadas hacen de esta isla el lugar apropiado para el establecimiento de itinerarios científicos, como los realizados en las XIV Jornadas de Paleontología. En este trabajo se presenta una información general sobre la geología y paleontología de la isla de Fuerteventura, además de otra información adicional de las localidades visitadas en dos itinerarios científicos. El objetivo de estos itinerarios fue la observación de los materiales de las diferentes formaciones del Complejo Basal y de una parte representativa de las formaciones sedimentarias marinas y continentales con contenido fosilífero.

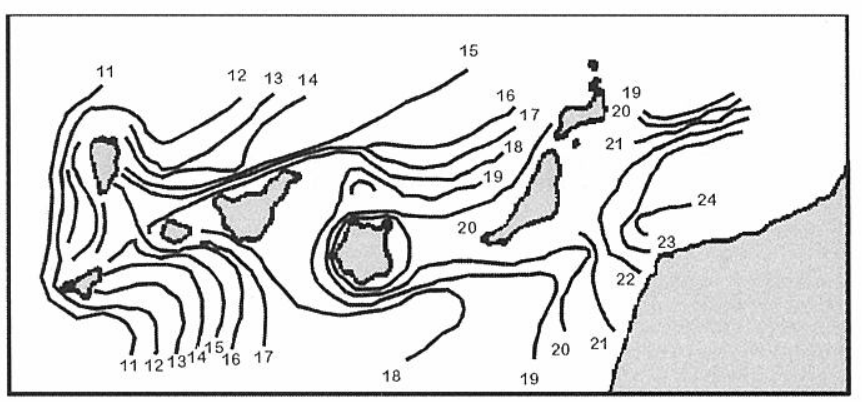

Figura 2. Distribución del espesor de la corteza terrestre, en kilómetros, en el ámbito de las Islas Canarias (tomada de Bosshard y Macfarlane, 1970).

Crustal thickness $(\mathrm{km})$ distribution around the Canary Islands (taken from Bosshard and Macfarlane, 1970).

\section{MARCO GEOGRÁFICO DE FUERTEVENTURA}

Es posible distinguir en Fuerteventura cinco comarcas fisiográficas claramente diferenciadas (Criado, 1991):

1. El Norte. Abarca los espacios situados al norte de la línea constituida por el barranco de Tebeto, La Oliva y Montaña Escanfraga. Se trata de un área con escasos desniveles y con una altitud que, salvo algunos puntos concretos (Montaña Tindaya y Montaña de la Arena), no supera los $200 \mathrm{~m}$. Esta parte de la isla está constituida fundamentalmente por pequeños conos de escorias y malpaíses, producidos en erupciones relativamente recientes de los últimos episodios del segundo ciclo de vulcanismo subaéreo plio-cuaternario y del vulcanismo subreciente.

2. El Valle Central. Al sur de Montaña Quemada se abre la llanura interior, que es una de las regiones fisiográficas más características de la isla. Esta llanura aparece alterada por la presencia de pequeños tableros alargados de una veintena de metros de altura y algunas montañas que se levantan un centenar de metros sobre el relieve circundante, como Montaña Gairía. Hacia el sur, el Valle Central se estrecha progresivamente hasta desaparecer en el Valle del Tarajal de Sancho. Esta llanura central constituye un bloque hundido con respecto al sector más occidental, y su origen ha estado condicionado por la actividad tectónica.

3. Los Valles y Cuchillos orientales. Esta unidad se localiza desde Montaña Escanfraga, al norte, hasta el Istmo de Jandía, al sur. La característica esencial es la presencia de un relieve que se estructura en valles, la mayoría sin cabeceras bien desarrolladas, con vertientes cóncavas y fondo plano. Los interfluvios están constituidos por cordales que normalmente superan los $400 \mathrm{~m}$ (cuchillos). Estos cuchillos representan los restos de los edificios volcánicos subaéreos del ciclo de vulcanismo miocénico.

4. El Macizo de Betancuria. Este macizo se localiza desde el curso medio del Barranco de Los Molinos, al norte, hasta el margen occidental del barranco de Chilegua. El contacto con la llanura central es bastante brusco, sobre todo entre Antigua y Tuineje. Este macizo presenta, como rasgos diferenciales, acusados desniveles y una notable 
compartimentación del relieve. En este sector afloran los materiales del Complejo Basal.

5. La Península de Jandía. Separada del resto de la isla por el Istmo de la Pared, presenta dos vertientes claramente diferentes. La vertiente de Barlovento presenta un talud cóncavo y un escarpe donde se alcanzan las mayores cotas de la isla (Pico de la Zarza, $807 \mathrm{~m}$ ). La vertiente de sotavento se caracteriza por la presencia de una red de barrancos estrechos y cortos, en disposición casi radial que parten del escarpe. Desde Morro Jable hasta el oeste, los barrancos terminan en una planicie costera, levantada unos 10 metros sobre el nivel del mar. Algunos sectores como el Istmo de Jandía o el Jable de Salinas, se caracterizan por la presencia de formaciones dunares de arenas organógenas movilizadas por el viento, y sobre las que se han producido importantes encostramientos.

\section{CARACTERÍSTICAS GEOLÓGICAS Y REGISTRO PALEONTOLÓGICO}

Desde el punto de vista geodinámico, el Archipiélago Canario, y por tanto Fuerteventura, está situado dentro de la Placa Africana, en una posición tectónica de intraplaca, en ambiente oceánico y cercano al borde continental de tipo "pasivo" del noroeste africano. El espesor de la corteza oceánica bajo Canarias varía desde los $12 \mathrm{~km}$ en La Palma hasta los $20 \mathrm{~km}$ entre Fuerteventura y Lanzarote (Fig. 2, Bosshard y Macfarlane, 1970; Banda et al., 1980; Banda et al., 1981). La Isla de Fuerteventura se asienta sobre una corteza de espesor anormalmente grueso para ambientes oceánicos (entre 15 y $20 \mathrm{~km}$ ), que puede ser interpretada como oceánica engrosada o incluso como corteza de transición. Su estructura consiste (Banda et al., 1980; Banda et al., 1981) en una primera capa de rocas volcánicas que se extiende hasta los $3 \mathrm{~km}$ de profundidad, y una capa de rocas ígneas plutónicas de posible composición gabroica y ultramáfica que alcanza los $15 \mathrm{~km}$. Entre los 15 y $20 \mathrm{~km}$ aparece una zona de tránsito entre la corteza oceánica y el manto terrestre (Fig. 3) caracterizada por una baja velocidad de propagación de las ondas sísmicas $\mathrm{P}(7,4 \mathrm{~km} / \mathrm{s})$ si la comparamos con la velocidad de propagación en el manto $(8,0 \mathrm{~km} / \mathrm{s})$. Esta capa puede corresponder a un conjunto de rocas máficas y ultramáficas producidas por el magmatismo asociado a la actividad del punto caliente mantélico en el pasado (Holik et al., 1991). Esta capa de baja velocidad sísmica ha sido encontrada en otros contextos de magmatismo intraplaca (Caress et al., 1995).

En el conjunto del Archipiélago es posible reconocer la existencia de directrices o direcciones estructurales de primer orden que indican la presencia de importantes fracturas o fallas en la corteza oceánica. Las orientaciones de estas fracturas parecen concentrarse en cuatro grandes poblaciones fundamentales o directrices (Carracedo, 1984) que han condicionado la génesis y formación del Archipiélago y están íntimamente ligadas a la evolución tectónica del Océano Atlántico, al desplazamiento de la placa Africana y al campo de esfuerzos local provocado por la existencia de una pluma mantélica (Anderson et al., 1992):

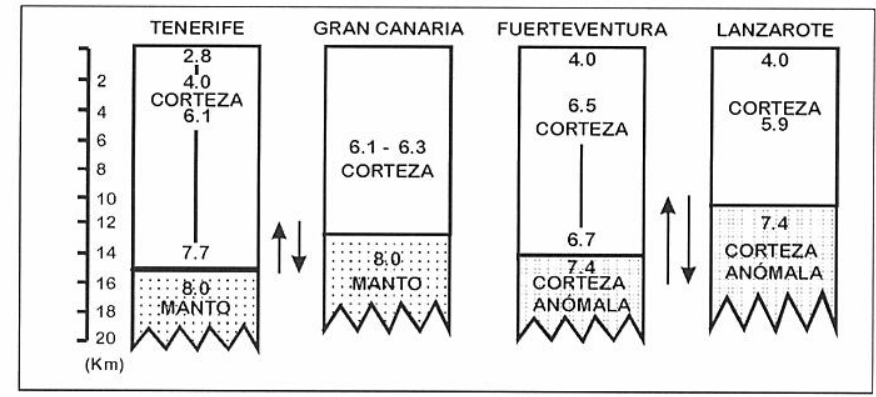

Figura 3. Estructura de la corteza terrestre bajo algunas islas del Archipiélago Canario. Las cifras indican la velocidad de propagación de las ondas $\mathrm{P}$ en $\mathrm{km} / \mathrm{s}$ (tomada de Banda et al., 1980 y 1981).

Crustal structure for some of the Canary Islands. Numbers indicate seismic $P$ wave velocities $(\mathrm{Km} / \mathrm{s})$ (taken from Banda et al., 1980 and 1981).

1. N35E (NE-SO). Dirección "Africana” (alineación de Fuerteventura y Lanzarote).

2. N1 $10^{\circ} \mathrm{E}(\mathrm{NO}-\mathrm{SE})$. Dirección "Atlántica" (alineación entre La Palma, Tenerife y Gran Canaria).

3. N60-65² E Dirección "Atlántica" (alineación entre Tenerife, La Gomera y El Hierro).

4. N-S. Orientación de la red de diques en la Palma.

El nacimiento y emersión de la Isla de Fuerteventura y su posterior evolución se ha llevado a cabo, de forma similar a como ocurre en las otras islas, según dos ciclos fundamentales: crecimiento submarino y subaéreo, que han dado lugar a la formación de diversas rocas representadas en la Isla por cuatro grandes formaciones rocosas (Ancochea et al., 1993, ver Figura 1):

- El Complejo Basal.

- Los restos de los edificios volcánicos subaéreos del primer ciclo de vulcanismo del Mioceno.

- Los restos de los edificios volcánicos subaéreos del segundo ciclo del Plio-Cuaternario.

- Sedimentos plio-cuaternarios.

\section{EL COMPLEJO BASAL}

En la Isla de Fuerteventura aflora fundamentalmente en el sector occidental, en el Macizo de Betancuria. Está esencialmente representado por un conjunto de materiales volcánicos submarinos apoyados sobre una serie sedimentaria de fondo oceánico de edad Jurásico inferiorCretácico inferior y medio (Steiner et al., 1998).

\section{Secuencia mesozoica}

La secuencia sedimentaria pre-volcánica mesozoica aparece en dos sectores de la costa occidental de la isla: entre la Punta de la Laja y la playa de Jarubio en la costa norte (Fúster et al., 1968b; Robertson y Stillman, 1979b; Roberston y Bernouilli, 1982), donde se encuentra muy fracturada e hidrotermalizada, y entre el Puerto de la Peña y la Caleta de la Peña Vieja en Ajuy (Fúster et al., 1968b; Rothe, 1968; Robertson y Stillman, 1979a; Fúster et al., 
1980; Roberston y Bernouilli, 1982; Fúster et al., 1984a; Fúster et al., 1984b; Renz et al., 1992). En este último sector, esta secuencia presenta un espesor aproximado de $1.600 \mathrm{~m}$. Se han diferenciado cinco unidades en estos sedimentos (Steiner et al., 1998):

- Unidad Basal. En la base de la secuencia, los sedimentos mesozoicos están intercalados con basaltos toleíticos de tipo N-MORB, de edad Jurásico Inferior, que representan los materiales más antiguos de la corteza oceánica en el Atlántico Central. Estos basaltos aparecen en la Playa de Los Muertos. Los basaltos están cubiertos por unos 150 metros de argilitas y limolitas depositadas en aguas profundas, por debajo del nivel de compensación de carbonatos.

- Unidad de Calizas con bivalvos pelágicos. Aflora en el Barranco de Ajuy y a lo largo de la costa, al norte del Puerto de la Peña. Consiste en unos 150 metros de calizas, argilitas y margas. En las margas aparecen numerosas impresiones del bivalvo Bositra buchi, identificadas por Rothe (1968) como Posidonia bronni. La asociación de facies de esta unidad indica que la sedimentación se produjo entre la parte media del talud continental y la llanura abisal, por encima del nivel de compensación de carbonatos. La edad de esta unidad es Jurásico Inferior- Jurásico Superior.

- Unidad Clástica Mixta. Aflora a lo largo de la costa, entre la Caleta Negra y la desembocadura del Barranco de la Peña, con una potencia de 470 metros. Marca el retorno a la sedimentación clástica y está compuesta principalmente por arenas y limos turbidíticos, con margas y pizarras negras subordinadas, depositadas en un ambiente marino profundo. Los foraminíferos y el alga verde encontrada en el techo de esta unidad aportan una edad Jurásico-Cretácico Inferior (Nautiloculina sp., Mesoendothyra sp. y Ophatalmidium sp.) y Oxfordiense a Valanginiense (Salpingoporella pygmaea).

- Unidad Clástica Principal. Aflora a lo largo de la costa entre la desembocadura del Barranco de la Peña y el sur de la Caleta de la Peña Vieja, y está compuesta por 500 metros de arenas turbidíticas. La base, de edad ValanginienseHauteriviense, se ha datado a partir de la aparición del ammonites Neocomites sp. (Renz et al., 1992). Los últimos 100 metros de esta unidad están compuestos principalmente por pizarras negras que marcan el final del sistema de abanico submarino. Considerando la edad de la siguiente unidad, las pizarras negras podrían corresponderse con el más antiguo de los eventos oceánicos anóxicos del Cretácico (Berriasiense- Albiense; Jenkyns, 1980).

- Unidad de Calizas Pelágicas. Aflora principalmente en la Caleta de la Peña Vieja y en la parte media del Barranco de la Peña. Está compuesta por 150 metros de depósitos de talud, principalmente margas. Se corresponde con la unidad F y G de Robertson y Stillman (1979). Robertson y Bernoulli (1982) asignan una edad Albiense-Cenomaniense Inferior a la unidad $\mathrm{F}$ basándose en la aparición del ammonites Partschiceras cf. whiteavesi y a la siguiente asociación de foraminíferos planctónicos: Schakoina galdolfii Reichel, Rotalipora sp., Hedbergella sp. y Gabonella sp. A la unidad $\mathrm{G}$ se le atribuye una edad Senoniense por la presencia de Globotruncánidos y Heterohelícidos, asociados con foraminíferos bentónicos de los géneros Stensioina, Gavelinella, Polymorphina y Reussella.

\section{Secuencia volcánica submarina}

La formación volcánica submarina aparece formando la mayor parte del Complejo Basal (Robertson y Stillman, 1979 a y b; Roberston y Bernouilli, 1982; Fúster et al., 1984 a y b; Ibarrola et al., 1989) y está intensamente intruida por rocas plutónicas posteriores y una densa red filoniana. Está constituida esencialmente por brechas, hialoclastitas y "pillow-lavas" o lavas almohadilladas de composición basáltica y traquibasáltica afectadas por un intenso metamorfismo hidrotermal en facies de esquistos verdes o epidota-albita. Entre la Caleta de la Peña Vieja y el barranco del Tarajalito se observa cómo la base de esta formación se apoya, según una paraconformidad, sobre la serie mesozoica.

La base de esta serie presenta buzamientos muy altos y llega a estar invertida en algunos puntos. Esta deformación, similar a la que afecta a los sedimentos cretácicos, se ha interpretado por el efecto de una cizalla dextra de dirección NS (Robertson y Stillman, 1979). El resto de la secuencia se halla en posición normal con ligeros buzamientos al oeste. Se han diferenciado tres unidades (Fig. 4) en estos sedimentos (Robertson y Stillman, 1979):

- Unidad A: Calizas pelágicas y bioclásticas. Esta unidad está compuesta por alternancias rítmicas de calcarenitas bioclásticas y calcilutitas limosas. El tamaño de grano y el espesor de los estratos de las calcarenitas aumenta hacia el techo de la unidad. Presentan cuerpos esféricos de más de 5 $\mathrm{cm}$ con laminación concéntrica que incorporan conchas finamente fragmentadas.

- Unidad B: Calcarenitas bioclásticas y calcirruditas conglomeráticas. Está compuesta por capas amalgamadas que gradan desde conglomerados a calcarenitas y a calcilutitas, con intraclastos de pizarras negras dispersos. Hacia el techo decrece el tamaño de grano y aparecen intercalaciones de areniscas y limolitas volcanoclásticas.

- Unidad C: Calcarenitas y areniscas volcanoclásticas.

En los sectores septentrional y meridional del Complejo Basal esta formación volcánica submarina parece pasar gradualmente a las coladas basálticas subaéreas de la base de los edificios volcánicos del Mioceno (Ancochea et al., 1993).

\section{Intrusiones}

Las rocas de la serie mesozoica y de la serie volcánica submarina están profusamente atravesadas por numerosos cuerpos plutónicos e hipoabisales. Las intrusiones plutónicas forman una serie de pequeños cuerpos independientes cuyas relaciones de contacto mutuo indican cuatro episodios mayores de actividad ígnea (Fúster et al., 1968 a; Gastesi, 1969 a y b; Stillman et al., 1975; Fúster et al., 1980, 1984 a y b; Le Bas et al., 1986; Stillman, 1987; Sagredo et al., 1989; Hoernle y Tilton, 1991; Cantagrel et al., 1993):

- Una serie ultraalcalina inicial que aparece esporádicamente cerca de la costa occidental de la isla, desde Tostón Cotillo al norte (Fúster et al., 1980; Barrera et al., 1986), hasta las proximidades de la desembocadura del barranco de Amanay al sur (Le Bas, 1981; Ahijado y Hernández-Pacheco, 1992; Ahijado et al., 1992; Mangas et 
(b)

(a)
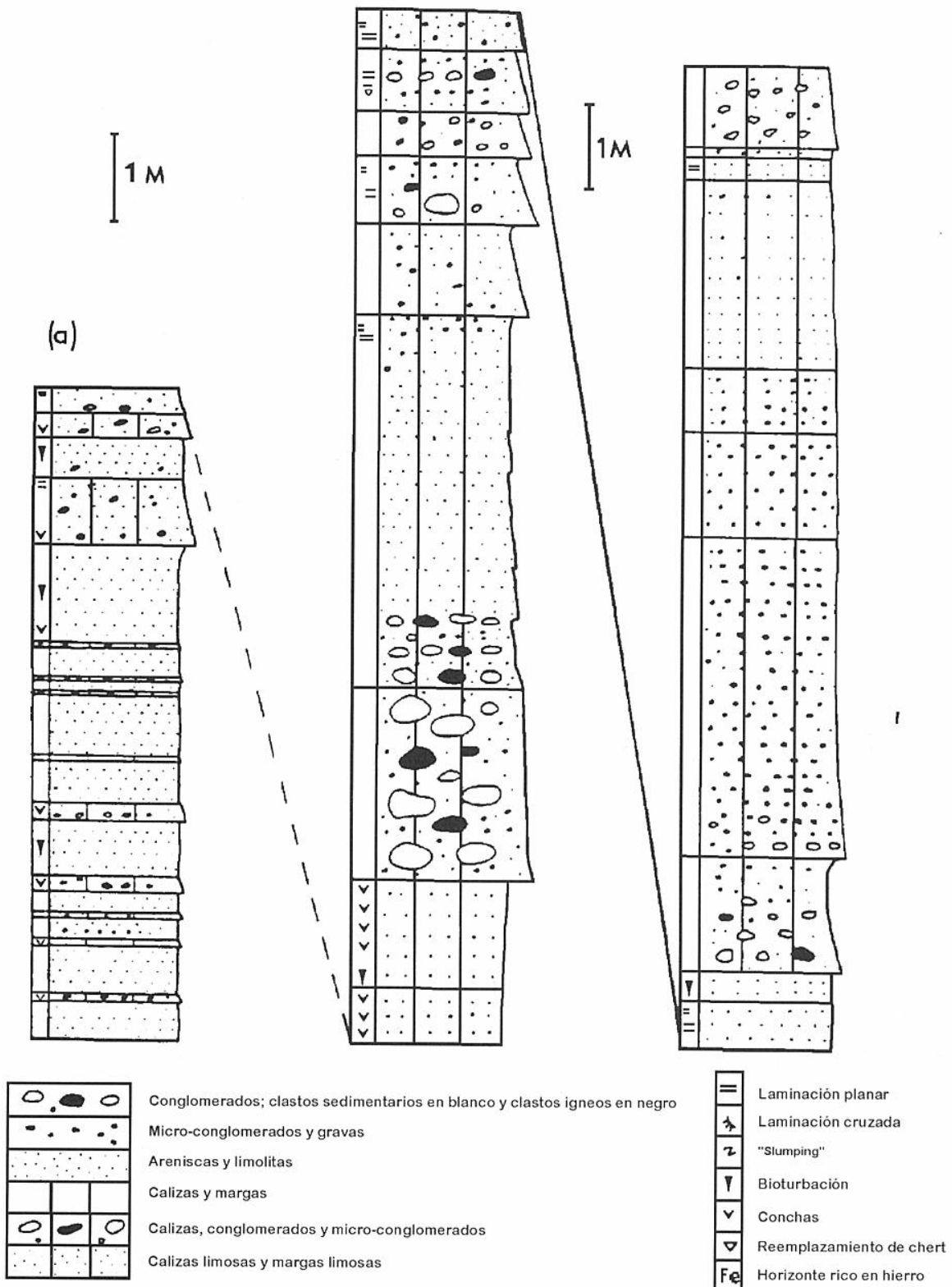

Figura 4. Columnas estratigráficas de las unidades A y B de la secuencia sedimentaria Oligocena. (Modificada de Robertson y Stillman, 1979).

Stratigraphic columns of the A and B units of the Oligocene sedimentary succession (modified from Robertson and Stillman, 1979).

al., 1994). Se trata fundamentalmente de intrusiones piroxeníticas, gabros anfibólicos y sienitas nefelínicas.

- Una serie ultraalcalina constituida por ijolitas-sienitas nefelínicas y carbonatitas que forman tres macizos: Punta del Peñón Blanco, Caleta de la Cruz-Punta de la Nao y Esquinzo (Barrera et al., 1986; Hernández-Pacheco, 1989; Ahijado y Hernández-Pacheco, 1990, 1992; Ahijado et al., 1992; Mangas et al., 1992; Mangas et al., 1993; Mangas et al., 1994).

- Una serie gabroide-piroxenítica constituida por plutones de forma alargada según la dirección NNE-SSO y NO-SE (Gastesi, 1969a y b, 1973) cuya intrusión produce intensos fenómenos de metamorfismo de contacto en las rocas encajantes (Muñoz y Sagredo, 1975; Stillman et al., 1975; Muñoz y Sagredo, 1989).

- Varios complejos circulares que forman una serie de intrusiones anulares de gabros y sienitas, como el de Vega de Río de Palmas, que dan lugar en el terreno a la aparición de crestas circulares, como la que se encuentra en el embalse de Las Peñitas (Muñoz, 1969).

Además de estas intrusiones plutónicas atravesando las rocas del Complejo Basal aparece un importante complejo filoniano (Fig. 5) constituido por una red de diques de extraordinaria densidad, que en muchos casos constituyen el 


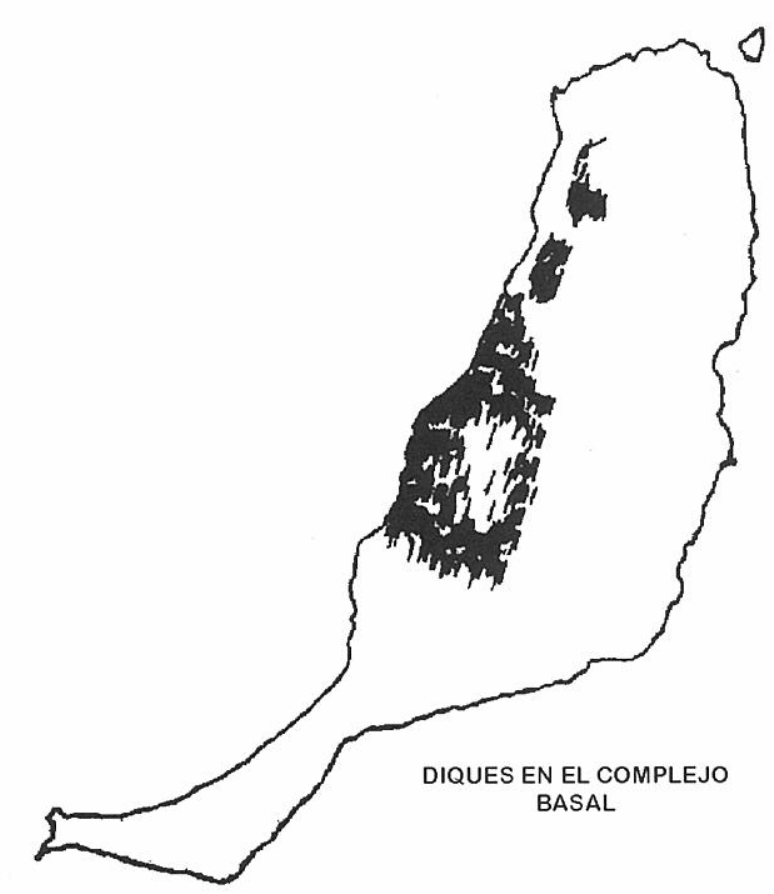

Figura 5. Posición de los enjambres de diques en la isla de Fuerteventura (tomada de Fúster et al., 1968 y Ancochea et al., 1993).

Distribution of dyke swarms in Fuerteventura Island (from Fúster et al., 1968 and Ancochea et al., 1993).

95\% o 99\% del afloramiento rocoso (Fúster et al., 1968a; López-Ruiz, 1970; Stillman y Robertson, 1977; Stillman, 1987). Suelen disponerse en posición subvertical o ligeramente inclinados hacia el oeste. La dirección más corriente es NNE-SSO, aunque también aparecen algunos con dirección NE-SO y NO-SE. Su composición es variable predominando los tipos basálticos y traquibasálticos.

Las rocas plutónicas de la serie ultraalcalina inicial y los complejos carbonatíticos están afectadas por zonas de cizalla dúctil o dúctil-frágil (Casillas et al., 1994; Fernández et al., 1997) en las que se desarrolla una importante foliación milonítica de dirección NO-SE con buzamientos variables tanto al Norte como al Sur con movimientos transcurrentes y de falla normal.

\section{ITINERARIO CIENTIFICO 1: FORMACIONES DEL COMPLEJO BASAL}

Parada 1: Formación sedimentaria mesozoica. Playa de los Muertos. Puerto de la Peña

En el afloramiento de la Playa de los Muertos podemos observar los niveles más bajos de la unidad basal de la secuencia mesozoica, que muestran el tránsito de las capas 1 y 2 de la corteza oceánica jurásica en este sector del Atlántico (Steiner et al., 1998). Se trata de una serie de flujos de basaltos toleíticos (con características geoquímicas de N-MORB) que se encuentran muy deformados. En estos niveles es posible adivinar alguna estructura almohadillada.

Más hacia el norte (parte más septentrional de la Playa de los Muertos y en el Puerto de la Peña) comienzan a aparecer una secuencia alternante de argilitas y limolitas que representan un conjunto de turbiditas de abanico submarino profundo. Estos niveles se encuentran en posición vertical o

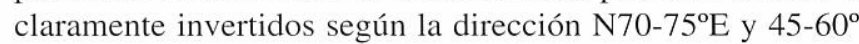
SSE y afectados por una densa red de fracturas que llegan a constituir una verdadera esquistosidad de fractura según la dirección EN-SO.

Toda esta unidad se haya atravesada por diques de sienitas nefelínicas-carbonatitas (los más antiguos), y diques basálticos y traquíticos (los más tardíos).

En el Puerto de la Peña (Fig. 6), por encima de los sedimentos cretácicos y en posición discordante, se sitúa una playa levantada pliocena, constituida por arenas y conglomerados. Encima de ellos aparecen coladas basálticas subaéreas que pasan hacia el mar formando lavas almohadilladas e hialoclastitas.

En la parte más alta del acantilado la playa levantada contiene numerosos cantos rodados de coladas basálticas y tobas palagoníticas. El acantilado termina en un depósito de arenas litorales y eólicas que se encuentran interestratificadas con conglomerados aluviales.

\section{Parada 2: Formación sedimentaria del Oligoceno. Barranco de la Fuente Blanca}

En el barranco de la Fuente Blanca aparecen sedimentos bioclásticos intensamente intruidos por diques y fracturados. Se apoyan sobre niveles de lavas almohadilladas y brechas de fragmentos de almohadillas, representando la parte más alta de la secuencia volcánica submarina. Fueron descritos por primera vez por Fúster y Aguilar (1965). Contienen numerosos foraminíferos bentónicos bien conservados, fragmentos de equinodermos, rodolitos de algas, briozoos, fragmentos de corales y bivalvos.

Estos sedimentos tienen una edad comprendida entre el Oligoceno Inferior y Medio, determinada a partir de la asociación de Eulepidina dilatata, Nephrolepidina praetournieri, Hesterostegina sp., Cycloclypeus sp., Spiroclypeus y Pararotalaia viennoti (Robertson y Bernoulli, 1982). Se depositaron a través de flujos gravitatorios ("debris flow") en un ambiente marino abierto. La fauna asociada indica que el área fuente se hallaba en aguas someras y que eran arrecifes que circundaban a la isla antes de emerger o incluso ya emergida, puesto que en la secuencia se encuentran cantos de rocas plutónicas y volcánicas que debían estar erosionándose en ese momento (Robertson y Bernoulli, op.cit.).

En la base, los sedimentos conforman una secuencia grano y estratocreciente con alternancias de calcirruditas y calcarenitas. En algunos de estos niveles aparecen foraminíferos bentónicos de gran tamaño. La inestabilidad en la cuenca en el momento del depósito se aprecia por la presencia de "slumps" y de grandes intraclastos de calizas bioclásticas. Hacia el techo aparecen niveles brechoides compuestos por cantos heterométricos de muy diversa naturaleza. Contienen cantos volcánicos, tanto sálicos como 


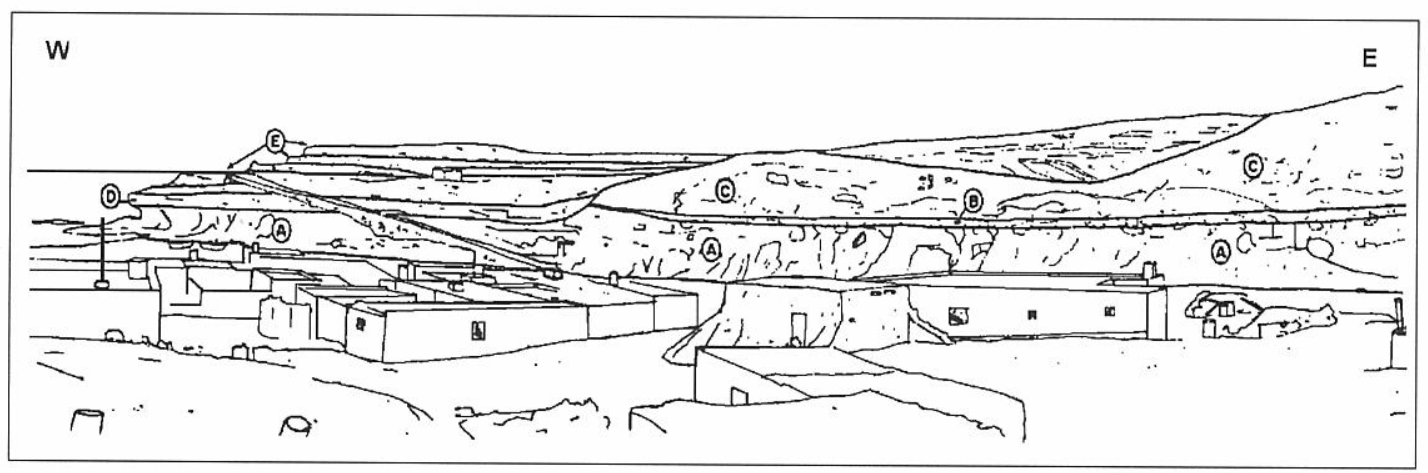

Figura 6. Esquema donde se muestran las relaciones entre el Complejo Basal y las formaciones pliocuaternarias en el Puerto de la Peña (tomado de Fuster et al., 1980). A = Ritmitas mesozoicas cortadas por diques. B = Playa levantada con conglomerados y arenas de edad Plio-cuaternaria. $\mathrm{C}=$ Coladas basálticas de la Serie II mostrando características subaéreas hacia el este y estructuras almohadilladas con tuffs palagoníticos hacia el oeste. D = Playa levantada cuaternaria con cantos de las coladas basálticas y de los tuffs palagoníticos. E = Arenas costeras y eólicas intercaladas con sedimentos de grano grueso de tipo barranco.

Sketch showing the relationships between the Basal Complex and the Pliocene-Quaternary formations at Puerto de la Peña (taken from Fúster et al., 1980): A: Mesozoic ritmites crossed by dykes. B: Raised beach with conglomerates and sands of Plio-quaternary age. C: Basaltic flows from Series II, they show subaerial features eastwards and pillow structures with palagonitic tuffs seawards. D: Quaternary raised beach with pebbles from basaltic flows and palagonitic tuff. E: Coastal and eolic sands interlayered with coarse-sediments of barranco type.

básicos, cantos de gabros, cantos de chert (derivados de la secuencia sedimentaria cretácica), y abundantes fragmentos bioclásticos. Estas brechas suelen presentar bases erosivas y granoseleción positiva, pasando hacia el techo a niveles de calcarenitas y calcilutitas finamente estratificadas, donde abundan los foraminíferos planctónicos.

\section{Parada 3: Serie volcánica submarina. Playa del Valle}

La serie volcánica submarina aflora de forma continua en la costa occidental de Fuerteventura desde el contacto con los sedimentos cretácicos, en la Caleta de la Peña Vieja, hasta el Puertito de los Molinos.

En los alrededores de la Playa del Valle esta serie está representada por niveles de lavas almohadilladas y brechas de fragmentos de almohadillas.

Las lavas almohadilladas aparecen apiladas y tienen diámetros inferiores a un metro. Presentan un borde vítreo de pequeño grosor, formado por el enfriamiento brusco de la lava al entrar en contacto con el agua, así como anillos de vesículas concéntricos y fracturas radiales. Composicionalmente son basaltos piroxénicos con texturas microporfídicas.

El material "interpillow" es aquí escaso y está formado por esquirlas vítreas despegadas de las propias almohadillas y carbonatos. En otros puntos de la serie se han encontrado calizas micríticas con foraminíferos planctónicos ocupando los huecos entre las almohadillas.

Es frecuente que los tubos de lava se fragmenten al avanzar por los flancos del volcán submarino formándose brechas de fragmentos de almohadillas ("pillow fragment breccia", Staudigel et al., 1984; Schmincke, 1984; o "broken pillow breccia", Carlisle, 1963). En esta zona existen excelentes afloramientos de este tipo de brechas asociados a los niveles de "pillow lavas", donde se pueden observar las típicas formas de trozo de tarta en los fragmentos, generadas cuando las almohadillas se rompen a favor de las fracturas radiales. Estos fragmentos tienen el lado curvo vítreo y anillos de vesículas concéntricos. Estas brechas no suelen presentar ningún tipo de organización: el transporte sufrido suele ser muy reducido y su depósito está asociado a flujos gravitatorios en masa.

Toda la serie volcánica submarina se halla atravesada por un denso enjambre filoniano que en ocasiones tiene densidades superiores al $90 \%$. En este punto se observa además otra población de diques más antiguos, biotíticoanfibólicos, de bordes irregulares .

\section{Parada 4: Intrusiones. Las Carbonatitas de la Punta de la Nao}

En esta zona de la costa podemos observar uno de los afloramientos de carbonatitas de la isla de Fuerteventura. Se trata de rocas poco frecuentes que en nuestro caso tienen la peculiaridad de representar, junto a las encontradas en el archipiélago de Cabo Verde, uno de los escasos afloramientos de carbonatitas emplazadas en ambiente oceánico (Fúster et al., 1968a).

Las carbonatitas se encuentran asociadas a diversos tipos de rocas silicatadas alcalinas, fundamentalmente sienitas nefelínicas y en algún caso ijolitas. Forman tres Complejos localizados de norte a sur: Esquinzo, Ajuy-Solapa (Punta de la Nao-Caleta de la Cruz) y Punta del Peñón Blanco.

Los complejos sienítico-carbonatíticos se emplazaron hace aproximadamente $23 \mathrm{Ma}$, entre el Oligoceno y el Mioceno Inferior (Cantagrel et al., 1993) a favor de un sistema de fracturas de carácter frágil a dúctil-frágil. Las rocas encajantes son diversos tipos de piroxenitas alcalinas.

En los afloramientos mas septentrionales (Esquinzo y Punta de la Nao) forman diques de potencia métrica. En 
concreto, en el afloramiento de la Punta de la Nao podemos observar un dique compuesto formado por sienita nefelínicacarbonatita. Los diques de carbonatita pueden presentar ocasionalmente zonados mineralógicos bien definidos (Fúster et al., 1968a; Barrera et al., 1986).

El aspecto de los complejos meridionales (Caleta de la Cruz y Punta del Peñón Blanco) es radicalmente diferente. Aquí el emplazamiento se produce a favor de zonas de cizalla dúctil-frágil y las intrusiones sienítico-carbonatíticas sufren simultáneamente una intensa deformación y recristalización metamórfica (Fernández et al., 1997).

Las carbonatitas son rocas ígneas compuestas por más de un $50 \%$ de carbonatos. Se clasifican en función del tipo de carbonato predominante en tres grandes grupos: carbonatitas calcíticas o sövitas (calcita), carbonatitas dolomíticas (dolomita) y ferrocarbonatitas (siderita, ankerita) (Woolley y Kempe, 1989). Las carbonatitas de Fuerteventura son siempre variedades calcíticas formadas fundamentalmente por flogopita, feldespato potásico, augita egirínica, apatito y magnetita. En general, tanto las carbonatitas como las rocas a ellas asociadas se caracterizan por la abundancia y variedad de minerales accesorios, siendo algunos de ellos verdaderas curiosidades mineralógicas (pirocloro, circonolita, perovskita, circón). Estos minerales dan a la roca una composición caracterizada por la gran abundancia de algunos elementos químicos, como REE, $\mathrm{Nb}, \mathrm{Sr}, \mathrm{Na}$ o $\mathrm{Zr}$.

\section{EL VULCANISMO DEL PRIMER CICLO SUBAÉREO MIOCENO}

Sobre las rocas del Complejo Basal de Fuerteventura pueden aparecer dos tipos de materiales, cuya presencia indica la emersión de la isla sobre el fondo marino:

- Depósitos sedimentarios detríticos formados por encima del nivel del mar en clara discordancia erosiva: conglomerados poco seleccionados con cantos y bloques de rocas del Complejo Basal, originados en condiciones climáticas áridas mediante un transporte relativamente rápido.

- Coladas basálticas de la base de los edificios volcánicos de tipo escudo que representan el comienzo del vulcanismo subaéreo en tránsito gradual desde el vulcanismo submarino.

Este vulcanismo subaéreo cuya edad estaría comprendida entre los 23 Ma y los 13 Ma (Coello et al., 1992; Ancochea et al., 1993; Balcells et al., 1994; Ancochea et al., 1996) dio lugar en la isla a la construcción de tres edificios volcánicos en escudo (parecidos a los que aparecen en Hawai) cuyos centros principales de emisión se situarían al oeste de la pared de Jandía, entre Pájara y Toto, y al este del puertito de Los Molinos. Los restos de estos edificios se pueden observar en las laderas de los "cuchillos" que limitan los grandes valles en "U" de la parte oriental de la Isla. Estos volcanes se formaron por acumulación de grandes volúmenes de coladas de lavas muy fluidas y material piroclástico, en erupciones fisurales de altas tasas eruptivas (Ancochea et al., 1993, 1996).

Los materiales basálticos de estas formaciones están también profusamente atravesados por numerosos diques de diversa naturaleza y composición, y algunos pitones sálicos (p. ej. la Montaña de Tindaya) (Cubas et al., 1989).

\section{EL VULCANISMO DEL SEGUNDO CICLO SUBAÉREO PLIO-CUATERNARIO}

Una vez formados estos edificios volcánicos miocenos y tras un intenso período erosivo, a finales del Plioceno (5 Ma) se renueva la actividad volcánica y se forman una serie de pequeños volcanes en escudo, cuyas coladas de lava basáltica fueron rellenando algunos paleo-relieves: volcán de Ventosilla, volcán del Cercado Viejo, volcán de Betancuria y Antigua, etc.

Con posterioridad se producen algunas pequeñas erupciones que forman conos de cinder alineados a lo largo de fracturas y coladas derivadas de extensión variable (Cendrero, 1966).

Entre las formaciones volcánicas que representan este último ciclo, aparecen numerosos niveles de playas levantadas cuyo origen debe relacionarse con movimientos de elevación de bloques insulares y/o movimientos eustáticos.

\section{LAS FORMACIONES SEDIMENTARIAS DEL PLIOCENO Y CUATERNARIO. REGISTRO PALEONTOLÓGICO}

En estos materiales aparecen diferentes formaciones sedimentarias con restos de fauna de invertebrados y vertebrados que constituyen el registro fósil, aunque puntual, más amplio de Canarias.

Las asociaciones de fósiles más representativas del Plioceno y del Cuaternario de Fuerteventura corresponden a gasterópodos y bivalvos marinos, icnitas de himenópteros y gasterópodos terrestres, dentro de los invertebrados; tortugas gigantes, lagartos, perenquenes, lisas, aves, ratones, musarañas, focas, así como algunas especies de animales domésticos, entre los vertebrados. Los tipos de yacimientos más comunes correspondientes a estas épocas son los depósitos marinos litorales, los depósitos dunares y los tubos volcánicos.

En tres ocasiones, durante el tránsito Mio-Plioceno, durante el Pleistoceno superior y en el Holoceno, se producen depósitos marinos relacionados con episodios marinos transgresivos. Las playas levantadas correspondientes a los dos primeros episodios contienen faunas de invertebrados de aguas cálidas, mientras que en el último, se ha encontrado fauna similar a la que actualmente habita en el medio marino canario. A estos depósitos se les superpusieron formaciones dunares (Plioceno-Pleistoceno superior-Holoceno) con aluviones y paleosuelos intercalados que han quedado parcialmente cubiertas por lavas basálticas. Los tubos volcánicos son una de las principales fuentes de información paleontológica del Cuaternario de Canarias, y se asemejan en cuanto a su dinámica de deposición a los rellenos de fisuras cársticas, actuando como trampas (depósitos de concentración, Seilacher et al., 1985) donde se concentran el sedimento y los restos (Castillo et al., 1996 a y b). Los mecanismos de transporte identificados son las escorrentías, los fenómenos gravitacionales o decantación de finos a partir de corrientes de aire. 


\section{El Plioceno de Fuerteventura}

El registro paleontológico de Fuerteventura perteneciente a esta época corresponde en su mayoría a depósitos marinos y, en mucha menor medida, a terrestres. Esto se debe a que los afloramientos marinos han quedado expuestos sobre una plataforma de abrasión (rasa intermareal) situada sobre los materiales del Complejo Basal, mientras que los terrestres quedaron cubiertos por las coladas volcánicas posteriores. Los fósiles pliocénicos mejor conocidos son de invertebrados marinos, principalmente moluscos gasterópodos y bivalvos (ver Tabla 1).

Los depósitos marinos del tránsito Mioceno-Plioceno (datados entre 5,8 y $6,6 \mathrm{Ma}$ ) aparecen hoy situados normalmente a 10-14 $\mathrm{m}$ de altura sobre el actual nivel del mar, e incluso, debido a movimientos tectónicos diferenciales, a los $55 \mathrm{~m}$, como en Morro Jable. Están constituidos por conglomerados y areniscas de poca potencia $(1 \mathrm{~m})$, con gran riqueza en fauna y flora calcárea (algas incrustantes) tan extraordinaria que constituirán la materia prima (arenas biodetríticas) de los costrones calcáreos (Meco, 1977, 1993; Meco y Pomel, 1985).

En Fuerteventura han sido estudiadas numerosas localidades con depósitos marinos del Plioceno que se extienden a lo largo de la costa occidental de la isla, desde el Aljibe de la Cueva al norte hașta la Punta Cotillo en el sur. En la costa oriental sólo aparecen en la Península de Jandía, concretamente en Morro Jable (Meco, 1977). Las asociaciones de invertebrados de los depósitos marinos pliocenos varían de unas localidades a otras, pero todas ellas se caracterizan por la presencia de especies de carácter cálido, como Strombus coronatus (Playa del Aljibe de La Cueva; Puerto de la Peña), o las acumulaciones de Saccostrea cucullata en la Playa del Valle.

Existen pocos estudios paleontológicos sobre depósitos terrestres del Plioceno de Fuerteventura, y, en general, de todas las Islas. No obstante, en estos materiales arenosos calcificados (calcarenitas) aparecen restos de tortugas gigantes y gasterópodos terrestres pertenecientes al Plioceno inferior, aunque algunos depósitos pudieran ser del límite Mioceno -Plioceno.

Rothe y Klemmer (1991) hallaron en el Barranco de los Molinos restos de huevos pertenecientes a la tortuga extinta Testudo burchardi, que ya fue descubierta en 1926 en Adeje (Tenerife), lo cual sugería una amplia distribución de este reptil por todo el Archipiélago. Más tarde, estos restos, junto con otros procedentes del Barranco del Valle y Puerto del Rosario, han sido atribuidos a Geochelone sp. (Hutterer et al., 1997). La abundancia puntual de huevos de tortuga en el Barranco de Los Molinos hace pensar que se trataba de una zona de nidificación. El tamaño de los huevos alcanza los $6 \mathrm{~cm}$ de diámetro, lo que permite estimar una longitud del caparazón de aproximadamente $80 \mathrm{~cm}$. En esta localidad, Hutterer (1989) encontró, además, ejemplares fósiles de una babosa de la familia Parmacellidae (Parmacella (Cryptella) parvula), el primer gasterópodo terrestre de esta edad que se describe para Fuerteventura.
En Agua Tres Piedras, en el Istmo de la Pared, es donde mejor se pueden observar las formaciones dunares del Plioceno de Fuerteventura. Según Meco (1977) estas dunas se formaron por la removilización de arenas puestas al descubierto durante la fase de regresión del nivel del mar. Intercalados en estas dunas aparecen paleosuelos que indican varias pausas lluviosas durante este período.

\section{El Cuaternario de Fuerteventura}

Durante el Pleistoceno superior se produjeron varias oscilaciones positivas del nivel del mar debido a un aumento global de la temperatura durante los periodos interglaciares. Estos cambios han quedado registrados en las costas de Fuerteventura, en los depósitos que Meco et al. (1986) denominan Jandiense, y que pertenecen al menos a dos estadios isotópicos, 5 y 7 (Meco et al., 1992; Zazo et al., 1997), y que se sitúan a unos $5 \mathrm{~m}$ sobre el nivel del mar actual.

La playa levantada jandiense, cuya localidad tipo es Las Playitas (Gran Tarajal) (Meco et al., 1986) está constituida por areniscas muy cementadas de color claro con Strombus bubonius, sobre las que suele aparecer un conglomerado de unos 2 a $3 \mathrm{~m}$ de espesor que incluye numerosos cantos redondeados de basalto y que en su parte superior, que corresponde al comienzo de la postplaya, en la berma, no suele estar cementado y se mezcla con aportes continentales arcillosos y arenosos. Es el nivel de tempestades y presenta una fauna abundante pero poco diversa; incluye $1 / 4$ de especies senegalesas que no habitan hoy en día en las costas canarias. Strombus bubonius representa más del 6\%. El grupo de Patella es el más numeroso y alcanza más del 50\% (Fig. 7, Tabla 2) (Meco, 1988, 1993; Meco y Stearns, 1981; Meco y Pomel, 1985; Meco y Petit-Maire, 1986).

En el Holoceno se produce una nueva elevación del nivel del mar que da lugar a varios depósitos marinos cuya edad varía entre los 5.640 años y los 3.400 años, y se encuentran a 3-4 m sobre el nivel de la marea baja. Este episodio trangresivo fue denominado por Meco y Petit-Maire (1986) como Erbanense, y su localidad tipo es la Jaqueta (en el sur de Fuerteventura). Otros afloramientos son los de Corralejo y El Cotillo. Los restos de esta playa son eminentemente conglomeráticos con cantos rodados de la arenisca jandiense. Se encuentra directamente sobre la arenisca jandiense cuando corresponden al relleno de cubetas y sobre un delgado depósito continental de color asalmonado con clastos angulosos y conchas de gasterópodos terrestres en otras ocasiones. El punto más alto, correspondiente a la berma, se encuentra a casi dos metros de altura sobre la berma actual. La asociación faunística hallada se puede observar en la Tabla 3.

Las dunas eólicas están bien representadas por toda la isla. Los cambios del nivel del mar favorecieron el ataque de la base de los acantilados de la costa norte de la península de Jandía, dejando expuestas las calcarenitas y las areniscas grises cementadas, que, por acción del 


\begin{tabular}{|c|c|}
\hline \multicolumn{2}{|c|}{ Moluscos marinos del Plioceno de Fuerteventura } \\
\hline Clase Gastropoda & $\begin{array}{l}\text { Clase Bivalvia } \\
\text { Orden Arqueogastropoda }\end{array}$ \\
Familia Haliotidae & Familia Pectinidae \\
Haliotis tuberculata Linneo & Gigantopecten latissima Brocchi \\
Familia Patellidae & Chlamys pesfelis Linneo \\
Patella caerulea Linneo & Hinnites ercolanianus Cocconi \\
Fissurella rosea Gmelin & Familia Ostreidae \\
Diodora gracea Linneo & Saccostrea cuccullata Born \\
Familia Trochidae & Ostrea edulis Linneo \\
Gibbula filiformis De Rayneval & Familia Spondylidae \\
Familia Neritidae & Spondylus gaederopus Linneo \\
Nerita emiliana Mayer & Tellina strigosa Poli \\
Familia Naticidae & Subclase Heterodonta \\
Natica sp. & Familia Chamidae \\
Orden Mesogastropoda & Chama gryphoides Linneo \\
Familia Strombidae & Familia Carditidae \\
Strombus coronatus Defrance & Cardita calyculata Linneo \\
Familia Capulidae & Cardita ajar Linneo \\
Rothpletzia rudista Simonelli & Familia Cardiidae \\
Orden Neogastropoda & Rudicardium tuberculata Linneo \\
Familia Conidae & Laevicardium oblongum Gmelin \\
Conus pelagicus Linneo & Familia Tellinidae \\
Conus mercati Brocchi & Gastrana lacunosa Chemnitz \\
Familia Muricidae & Familia Lucinidae \\
Nucella plessisi Sowerby & Ctena eburnea Costa \\
Murex conglobatus Linneo & Linga columbella Lamarkc \\
Familia Olividae & Lucina leonina Deshayes \\
Ancilla glandiformis Lamarck & \\
\hline
\end{tabular}

Tabla 1. Relación de especies de gasterópodos y bivalvos de los depósitos costeros del Plioceno de Fuerteventura (modificado y ampliado de Meco, 1977).

Fossil record of gastropods and bivalves of Pliocene marine deposits of Fuerteventura Island (modified from Meco, 1977).

viento, formarán las dunas del Pleistoceno superior y del Tardiglacial en la zona del Istmo de Jandía y el norte de Fuerteventura (Meco, 1992). Dentro de estas dunas se pueden encontrar frecuentemente niveles con nidos de himenópteros y restos de gasterópodos como los de Theba costillae (Hutterer, 1990).

La alternancia de dunas y paleosuelos, así como el estudio de depósitos de materiales finos procedentes del Sahara, han permitido establecer las sucesiones de eventos paleoclimáticos de la isla de Fuerteventura (Meco, 1975; Meco y Petit-Maire, 1986; Rognon y Coudé-Gaussen, 1987, 1992; Rognon et al., 1989).

\section{Tubos volcánicos}

En Fuerteventura han sido estudiados numerosos yacimientos con fauna endémica de vertebrados, procedentes de tubos volcánicos y de pequeñas cavidades del malpaís. Entre ellos destacamos el yacimiento arqueológico de La Cueva de Villaverde (Garralda et al., 1981; Meco et al., 1982; Meco, 1992) y los yacimientos paleontológicos de la Cueva del Llano y la Cueva de Las
Palomas en la Oliva (Martín González et al., 1998b ; Coello et al., 1999; Mcminn et al., 1990).

La Cueva de Villaverde es la localidad tipo de la especie Malpaisomys insularis (Hutterer et al., 1988), un múrido endémico de Canarias que ha sido hallado en diversos yacimientos de Fuerteventura (Cofete, Los Gorriones, Hueso del Caballo, etc.), Lanzarote (Los Jameos del Agua) y La Graciosa (Hutterer et al., op. cit.). El estudio del esqueleto, su tamaño, su forma y nicho ecológico ha sido realizado por Boye et al., (1992). Según estos autores, se trata de una especie con adaptaciones en los miembros anteriores y posteriores para trepar, apto para su nicho ecológico inferido, el malpaís. Los estudios sobre su filogenia han sido llevados a cabo por Hutterer et al. (1988), que lo relacionan con Acomys y Uranomys. Un análisis de las albúminas fósiles de Malpaisomys ha dado como resultado el establecimiento de otra filogenia diferente a la obtenida con el estudio de las características morfológicas, estando éste más emparentado con el género Mus (Montgelard, 1991). En este tubo volcánico, asociado a Malpaisomys, se ha encontrado el género Mus, cuyas características 


\begin{tabular}{|l|c|}
\hline \multicolumn{2}{|c|}{ Moluscos marinos del Pleistoceno superior de Fuerteventura } \\
\hline Clase Gastropoda & Orden Neogastropoda \\
Orden Arqueogastropoda & Familia Conidae \\
Familia Patellidae & Conus testudinarius Bruguiere \\
Patella sp. & Conus papilionaceous Bruguiere \\
Familia Trochidae & Familia Muricidae \\
Gibbula aff. richardii Payraudeau & Thais haemastoma Linneo \\
Monodonta aff. turbinata Born & Murex saxatilis Linneo \\
Littorina punctata Linneo & Familia Buccinidae \\
Orden Mesogastropoda & Cantharus viverratus Kiener \\
Familia Cypraeidae & Familia Harpidae \\
Cypraea stercoraria Linneo & Harpa rosea Lamarck \\
Erosaria spurca Linneo & Familia Mitridae \\
Familia Vermetidae & Mitra fusca Swainson \\
Vermetus adansoni Daudin & Clase Bivalvia \\
Familia Cassididae & Sublase Pteriomorphia \\
Semicassis undulata Richard & Familia Ostreidae \\
Familia Tonnidae & Ostrea gasar Linneo \\
Tonna galea Linneo & Familia Spondylidae \\
Familia Bursidae & Spondylus gaederopus Linneo \\
Bursa pustulosa Reeve & Subclase Heterodonta \\
Familia Ranellidae & Familia Veneridae \\
Cymatium trigonum Gmelin & Venus verrucosa Linneo \\
Cymathium parthenopaeum von Salis & \\
Charonia nodifera Lamarkc & \\
Familia Strombidae & \\
Strombus bubonius Lamarck & \\
\hline
\end{tabular}

Tabla 2. Gasterópodos y bivalvos de los depósitos marinos del Jandiense de Fuerteventura (modificado y ampliado de Meco et al., 1986).

Gastropod and bivalve records from Jandiense marine deposits of Fuerteventura Island (modified from Meco et al., 1986).

osteológicas y dentarias particulares han llevado a Carrascosa y López-Martínez (1988), a proponer la adscripción de dicho material a una nueva subespecie de Mus musculus. La entrada en el archipiélago de esta especie, se hace coetánea con la entrada del hombre, aunque no se descarta una colonización anterior (Carrascosa y López Martínez, op. cit.). También se ha hallado en esta localidad la musaraña endémica Crocidura canariensis (Hutterer et al., 1987). Según Hutterer et al., (1992) esta especie está relacionada filogenéticamente con $C$. sicula como lo han mostrado los resultados de los análisis genético, de la vocalización y morfológico. Por último, cabe destacar los estudios sobre la fauna doméstica y la asociada a la actividad del hombre (Meco et al., 1982; Meco, 1992).

La Cueva del Llano es un tubo volcánico de edad pleistocena, que muestra en algunos tramos un relleno sedimentario de gran potencia y complejidad con respecto al resto de los tubos conocidos de Canarias. El relleno se efectuó en cinco etapas durante el Pleistoceno superior y el Holoceno, y presenta variaciones en la litología y granulometría de los sedimentos causadas por cambios en las condiciones internas de la sedimentación, y por la alternacia de periodos de menor y mayor pluviosidad (Coello et al., 1999). Los primeros datos sobre el estudio tafonómico de la fauna de vertebrados han permitido corroborar el origen escatológico de parte del depósito (parte cercana a la entrada), así como detectar un cambio en la dieta de la lechuza común en el Cuaternario (Martín González et al., 1998b; Castillo et al., en prensa).

La Cueva de las Palomas es la localidad tipo de la pardela Puffinus olsoni. Esta pardela, recientemente desaparecida en esta isla y en Lanzarote, poseía una talla intermedia entre $P$. puffinus y $P$. assimilis y sus hábitos eran similares a los de la actual especie $P$. puffinus (McMinn et al., 1990). Junto a la pardela aparecen restos de Mus musculus, Malpaisomys insularis y Crocidura canariensis.

En la Tabla 4 vienen recogidas las diferentes especies de vertebrados hallados en los yacimientos fosilíferos de Fuerteventura. 


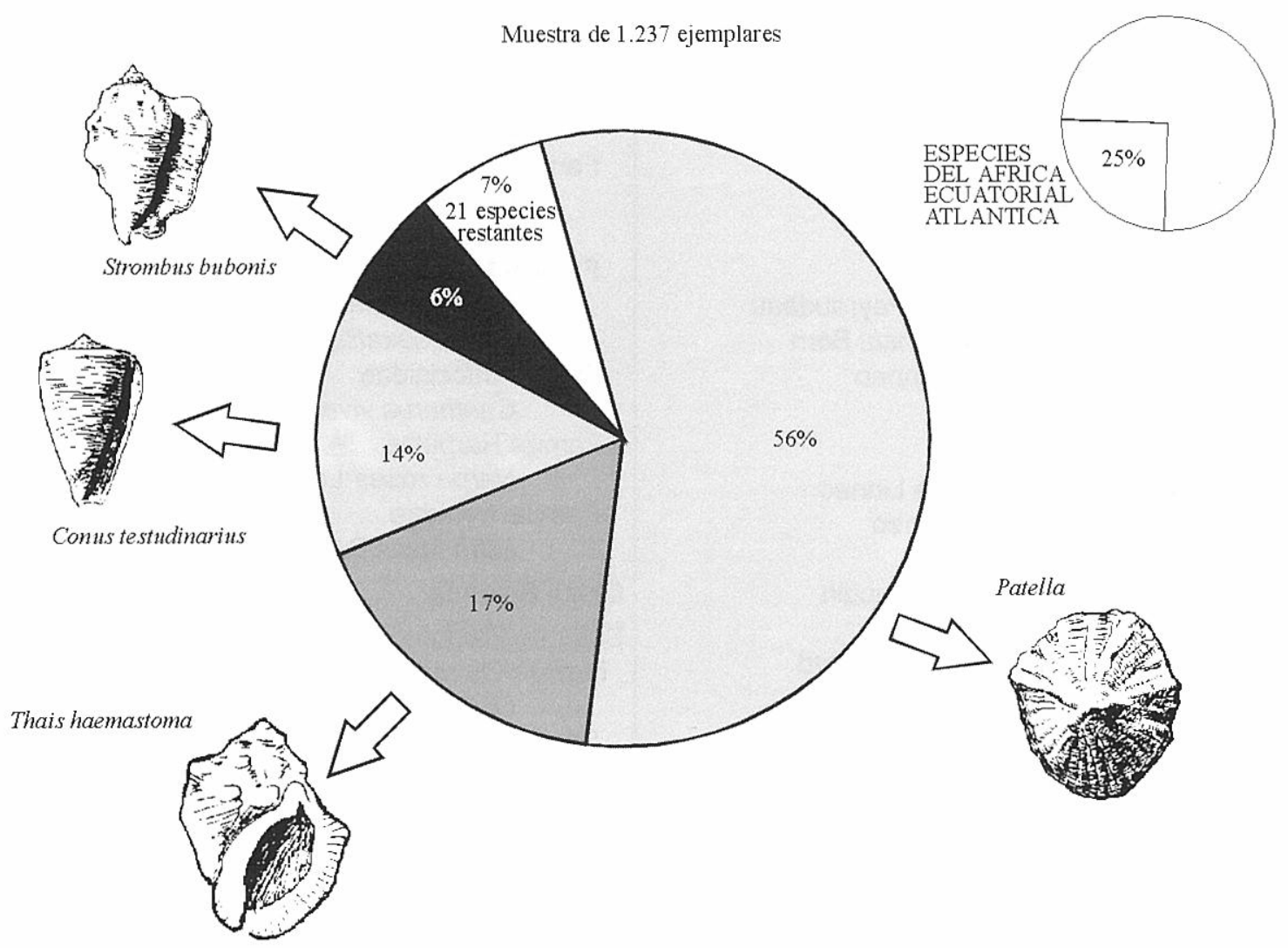

Figura 7. Fauna de invertebrados del Jandiense (tomada de Meco et al., 1986).

Jandiense invertebrate fossils (taken from Meco et al., 1986).

\section{ITINERARIO CIENTÍFICO 2: FORMACIONES SEDIMENTARIAS DEL PLIO-PLEISTOCENO. TUBOS VOLCÁNICOS}

\section{Parada 1: Depósitos marinos del Plioceno. Playa del Valle}

Los depósitos marinos del Plioceno se localizan a lo largo de unos $40 \mathrm{~km}$ de la costa occidental de la isla de Fuerteventura. Estos depósitos están bien representados en la localidad denominada Playa del Valle. El afloramiento es un depósito costero rocoso que se extiende lateralmente unos $100 \mathrm{~m}$ al sur de la Playa del Valle, y se sitúa a unos $20 \mathrm{~m}$ sobre el nivel del mar. Estos materiales se disponen en discordancia sobre los del Complejo Basal, y a techo están cubiertos por una costra calcárea. La columna estratigráfica de dos puntos de la secuencia de terrígenos de este yacimiento se puede observar en la Figura 8 (Martín González et al., 1998a). En depósitos equivalentes, por encima del nivel arenoso (tramo B de la columna 1) se encuentran coladas de la Serie II-A que han sido datadas en 5,0 \pm 0,3 Ma (Coello et al., 1992), y a techo de los depósitos aluviales (tramo $\mathrm{H}$ e I de la misma columna) se dispone otra colada datada en 3 Ma (Coello et al., 1992).

La secuencia estudiada comienza en un banco conglomerático que rellena las irregularidades erosivas del sustrato. Se continúa con un conglomerado con niveles intercalados de arenas finas a gruesas. Los conglomerados están formados por brechas polimícticas de cantos basálticos y traquíticos, además de bioclastos, y presentan una escasa granoselección. Por encima, la secuencia sigue hasta el techo con paquetes de conglomerados amalgamados de unos 10-15 $m$ de potencia. Entre los niveles conglomeráticos se reconocen algunas concentraciones de fósiles que a veces forman cuerpos continuos en la horizontal (hasta $0,5 \mathrm{~m}$ de potencia, N4 y N5). Se observan hasta 8 niveles fosilíferos de diversa composición faunística y conservación, algunos de los cuales se acuñan hacia el sur.

Entre las especies de invertebrados marinos más comunes se encuentran los arqueogasterópodos pateloides Patella cf. caerulea, Diodora cf. gracea y Fissurella cf. rosea, el ostreido Saccostrea cucullata, un cirrípedo balánido del género Tetraclita, y otros gasterópodos (Nerita emiliana; Natica sp.).

Entre las características tafonómicas de la fauna destacamos la frecuencia de empaquetamiento de las conchas de los pateloides, la desarticulación, la fragmentación y la disposición cóncava predominantemente hacia arriba de las conchas de los bivalvos, asi como la existencia de moldes externos o internos de gasterópodos y bivalvos. También aparecen evidencias de corrasión en la charnela y el umbo (presencia de facetas). En cuanto a la conservación de los restos es resaltable la escasez de trazas de especies perforadoras e incrustantes.

La secuencia ha sido interpretada (Martín González et al., 1998a) como un conjunto de materiales depositados en un ambiente de abanico deltaico basándose en la composición prácticamente terrígena de éstos. Su 


\begin{tabular}{|c|c|}
\hline \multicolumn{2}{|c|}{ Moluscos marinos del Holoceno de Fuerteventura } \\
\hline $\begin{array}{l}\text { Clase Gastropoda } \\
\text { Orden Arqueogastropoda } \\
\text { Familia Patellidae } \\
\text { Patella sp. } \\
\text { Familia Trochidae } \\
\text { Calliostoma dubium Linneo } \\
\text { Monodonta punctulata Born } \\
\text { Familia Naticidae } \\
\text { Natica lactea Guildin } \\
\text { Orden Mesogastropoda } \\
\text { Familia Cerithiidae } \\
\text { Cerithium vulgatum Bruguiere } \\
\text { Familia Cypraeidae } \\
\text { Luria lurida Linneo } \\
\text { Erosaria spurca Linneo } \\
\text { Familia Vermetidae } \\
\text { Vermetus adansoni Daudin } \\
\text { Familia Cassididae } \\
\text { Semicassis undulata Richard } \\
\text { Familia Bursidae } \\
\text { Bursa pustulosa Reeve } \\
\text { Familia Ranellidae } \\
\text { Cymatium trigonum Gmelin } \\
\text { Cymatium parthenopaeum von Salis } \\
\text { Charonia nodifera Lamarkc } \\
\text { Orden Neogastropoda } \\
\text { Familia Conidae } \\
\text { Conus mediterraneus Bruguiere } \\
\text { Conus papilionaceous Bruguiere } \\
\text { Familia Muricidae } \\
\text { Thais haemastoma Linneo } \\
\text { Murex saxatilis Linneo } \\
\text { Nassa aethiopica Linneo }\end{array}$ & $\begin{array}{l}\text { Familia Columbilidae } \\
\text { Columbella adansoni Linneo } \\
\text { Familia Buccinidae } \\
\text { Cantharus viverratus Kiener } \\
\text { Familia Harpidae } \\
\text { Harpa rosea Lamarck } \\
\text { Familia Mitridae } \\
\text { Mitra fusca Swainson } \\
\text { Familia Turridae } \\
\text { Clavatula bimarginata Lamarck } \\
\text { Familia Marginellidae } \\
\text { Marginella glabella Linneo } \\
\\
\text { Clase Bivalvia } \\
\text { Sublase Pteriomorphia } \\
\text { Familia Pectinidae } \\
\text { Chlamys flabellum Gmelin } \\
\text { Chlamys corallinoides Linneo } \\
\text { Familia Pinnidae } \\
\text { Pinna sp. } \\
\text { Subclase Heterodonta } \\
\text { Familia Carditidae } \\
\text { Cardita calyculata Linneo } \\
\text { Familia Cardiidae } \\
\text { Rudicardium tuberculata Linneo } \\
\text { Familia Lucinidae } \\
\text { Linga columbella Lamarkc } \\
\text { Codakia eburnea Lamarck } \\
\text { Familia Veneridae } \\
\text { Venus verrucosa Linneo }\end{array}$ \\
\hline
\end{tabular}

Tabla 3. Gasterópodos y bivalvos de los depósitos marinos erbanenses de Fuerteventura (modificado y ampliado de Meco et al., 1986).

Gastropods and bivalves records from Erbanense marine deposits of Fuerteventura Island (modified from Meco et al., 1986).

formación habría tenido lugar durante una etapa transgresiva, de forma que los niveles de arena se corresponderían con la fase de máxima subida del nivel del mar y el último tramo conglomerático reflejaría la progradación del abanico deltaico durante la alta parada del nivel del mar. Por lo tanto, esta secuencia representa un ciclo deposicional de profundización-somerización.

La fauna de invertebrados marinos que se encuentran en este depósito, pateloides, ostreidos y cirrípedos, y las características tafonómicas que presentan, sugieren que se depositaron en un ambiente somero de media-alta energía.

Algunas de las especies de esta rasa marina pliocena son de carácter cálido (Saccostrea cuccullata, Fisurella cf. rosea, Tetraclita sp.), al igual que otras estudiadas por Meco (1977) procedentes del Aljibe de la Cueva y Puerto de la Peña (Strombus coronatus, Gigantopecten latissimus, Ancilla glandiformis). Esto sugiere la influencia de un clima más cálido, con un desplazamiento hacia el norte de las bandas latitudinales tropicales durante este periodo.

Parada 2: Depósitos marinos del Pleistoceno superior. Matas Blancas

Los depósitos costeros del Pleistoceno superior de Fuerteventura han sido denominados como Jandiense por Meco et al. (1986); éstos se sitúan a unos $5 \mathrm{~m}$ sobre el nivel del mar actual. Aunque la localidad tipo de estos depósitos es Las Playitas, en Matas Blancas se observa un afloramiento importante que contiene una gran concentración de conchas del gasterópodo marino Strombus bubonius, fósil marcador de este periodo. Por otra parte, esta localidad es el único yacimiento 


\begin{tabular}{|c|}
\hline Vertebrados fósiles del Cuaternario de Fuerteventura \\
\hline $\begin{array}{l}\text { Clase Mammalia } \\
\text { Orden Rodentia } \\
\text { Familia Muridae } \\
\quad \text { Malpaisomys insularis Hutterer et al. } \\
\text { Mus musculus Linneo } \\
\text { Familia Soricidae } \\
\text { Crocidura canariensis Hutterer et al. }\end{array}$ \\
\hline $\begin{array}{l}\text { Clase Avian } \\
\text { Orden Procellariforme } \\
\text { Familia Procellariidae } \\
\text { Puffinus holeae Walker et al. } \\
\text { Puffinus olsoni Jaume et al. } \\
\text { Familia Accipitridae } \\
\text { Haliaeetus sp. } \\
\text { Familia Phasianidae } \\
\text { Coturnix gomerae Jaume et al. }\end{array}$ \\
\hline $\begin{array}{l}\text { Clase Reptilia } \\
\text { Orden Squamata } \\
\text { Familia Lacertidae } \\
\quad \text { Gallotia atlantica Peters y Doria } \\
\text { Familia Scincidae } \\
\text { Chalcides simonyi Steindachner } \\
\text { Familia Gekkonidae } \\
\quad \text { Tarentola angustimentalis Steindachner }\end{array}$ \\
\hline
\end{tabular}

Tabla 4. Especies de vertebrados halladas en los yacimientos cuaternarios de Fuerteventura. Vertebrate fossil records of the Quaternary sites of Fuerteventura Island.

paleontológico de Canarias que está declarado como Bien de Interés Cultural.

Las dataciones realizadas por Meco et al. (1992) los engloban en el estadío isotópico 5c o 5e (Eemiense); posteriormente Zazo et al. (1994, 1997) realizan nuevas dataciones que les llevan a concluir que estos depósitos corresponden a dos niveles altos del nivel del mar, pertenecientes a dos estadios isotópicos diferentes, el 5 y el 7. El Penúltimo Interglacial (estadío isotópico 7) está representado en Matas Blancas por un depósito de "fandelta", con abundantes restos de Strombus bubonius. Hacia tierra este depósito pasa lateralmente a sedimentos continentales, representando la desembocadura antigua de un río, que hoy día se corresponde al Barranco de Los Cuchillos. Este nivel ha sido datado con Th/U en $178 \pm 4$ ka. Por encima se dispone otro nivel marino más reciente (dispositivo “onlap"), constituido por un depósito de playa, también con numerosos restos de Strombus bubonius, que penetrando hacia tierra alcanza la cota de más de 2 m. La edad radiométrica de este nivel es de 103 \pm 2 ka (Zazo et al., 1997).

Estos últimos datos indicarían la llegada al litoral de Fuerteventura de especies de caracter cálido en el Penúltimo y Ultimo Interglacial, lo que sugiere un cambio climático en el Cuaternario de las islas. Este consistiría en el desplazamiento hacia el noroeste de la corriente fría de Canarias, permitiendo la pervivencia de S. bubonius y otras especies acompañantes (Cantharus viverratus, Siderastrea radians, Harpa rosea, etc.).

\section{Parada 3: Depósito marino del Holoceno. La Jaqueta}

La última elevación marina registrada en Canarias ha recibido el nombre de Erbanense (Meco et al., 1986), y está representada por depósitos marinos situados a una altura de 3 a $4 \mathrm{~m}$ sobre la actual marea baja. La localidad tipo de estos depósitos es La Jaqueta. El corte estratigráfico se puede observar en la Figura 9.

La fauna que contiene es idéntica a la actual, siendo la especie dominante el gasterópodo Thericium vulgatum. 
Otros elementos faunísticos muy abundantes en estos depósitos son las especies del género Patella. El yacimiento de la Jaqueta se ha datado radiocarbónicamente como de hace 1.400 años. En otros lugares de la isla, como Corralejo, depósitos similares a estos han dado una edad de hace 3.640 años.

La fauna erbanense es muy semejante a la que habita actualmente en Canarias (Tabla 3) y en ella no hay más elementos senegaleses que los que pudieran permanecer hoy día vivientes.

\section{Parada 4: Formaciones dunares Plio-Pleistocenas de Barlovento y Huesos del Caballo}

Las formaciones dunares que se visitan en esta parada se sitúan en el Istmo de La Pared, en la Península de Jandía, en el extremo sur occidental de Fuerteventura. El Istmo, de aproximadamente $5 \mathrm{~km}$ de ancho, posee un escaso relieve con altitudes máximas que no sobrepasan los $300 \mathrm{~m}$ (Alto del Banzar, Loma de La Ruda, Huesos del Caballo). Más al sur, en la Península de Jandía, se alcanzan las altitudes mayores de la isla ( $800 \mathrm{~m}$, Pico de la Zarza), donde aún persisten restos de la vegetación relicta del Terciario, la laurisilva.

Los materiales sobre los que se asientan las dunas eólicas corresponden a piroclastos y coladas basálticas de edad miocena (Coello et al., 1992). En un corte estratigráfico desde Barlovento a Sotavento (Fig. 10) se pueden distinguir tres formaciones dunares: las dunas pliocenas que afloran en la costa de Barlovento, las pleistocenas en Huesos del Caballo, y el "jable" actual o arenas móviles que cubren las anteriores.

En la parada de la costa de Barlovento observamos que sobre los materiales volcánicos miocénicos se dispone un depósito marino de muy pequeñas dimensiones y una formación dunar consolidada, de $30 \mathrm{~m}$ de potencia o más en algunos puntos, de edad pliocena. Estas arenas recubrieron casi toda la isla durante la regresión marina postmesiniense y fueron acumuladas por fuertes vientos nordatlánticos. Intercalados con estas calcarenitas aparecen aluviones en hiladas y lentejones que indican al menos cuatro pausas pluviosas en un régimen árido (Meco, 1993). Las dunas aparecen coronadas por paleosuelos que contienen numerosos nidos de himenópteros y, ocasionalmente, gasterópodos terrestres. La edad pliocena de la duna calcarenítica viene confirmada por la existencia de lavas que la cubren y que han sido datadas en $2,7 \pm 0,2$ Ma y 1,83 \pm 0,24 Ma por K/Ar. Sin solución de continuidad, sobre esta paleoduna se disponen las dunas del Pleistoceno superior de Huesos del Caballo (Fig. 10).

En las formaciones dunares de Huesos del Caballo, se observan tres dunas bien diferenciadas: gris, ocre y amarilla, que terminan en paleosuelos arcillosos rojos. Estos se caracterizan por la presencia de numerosos icnofósiles pertenecientes a nidos de himenópteros (Icneumónidos) presumiblemente de la familia Anthophoriidae. Comunmente estos icnofósiles se denominan como "nidos de Anthophora". Ellis y EllisAdams (1993) y La Roche (com. per.) basándose en las características estructurales de los nidos opinan que

\section{Columna 1}

Columna 2

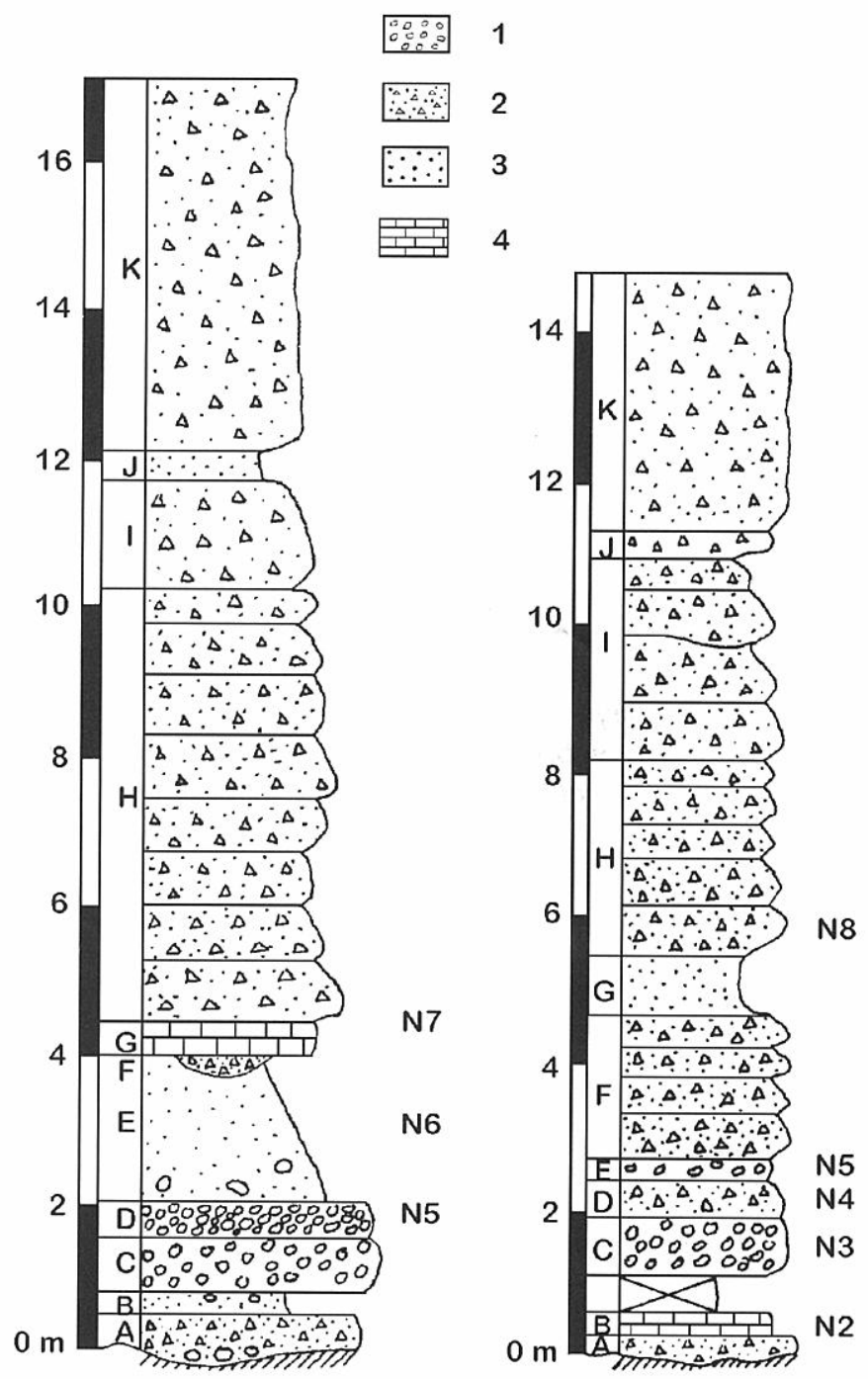

Figura 8. Columnas estratigráficas del depósito marino plioceno de la Playa del Valle. N1 a N8: niveles fosilíferos; 1: Conglomerados; 2: Brechas polimícticas; 3: Arenas; y 4: Nivel bioclástico cementado.

Stratigraphic columns of the Pliocene marine deposits from La Playa del Valle. N1 to N8: palaeontological beds; 1: Conglomerates; 2. Polymictic breccias; 3: Sands; and 4: Bioclastic cement level.

pertenecen a diferentes géneros distintos de Anthophora. Los gasterópodos terrestres también son muy abundantes en este afloramiento, destacando especies como Theba aff. arinagae, que se cree extinguida en Fuerteventura (Ibañez, com. per.), Obelus sp., Obelus despreauxii, Candidula ultima, Rumina decollata, Hemicycla sarcostoma y Pomatias adjuntus. También se pueden observar moldes calcareníticos de vegetales.

En el paleosuelo terminal de la duna amarilla, aparecen huevos y restos fósiles atribuidos a la pardela 


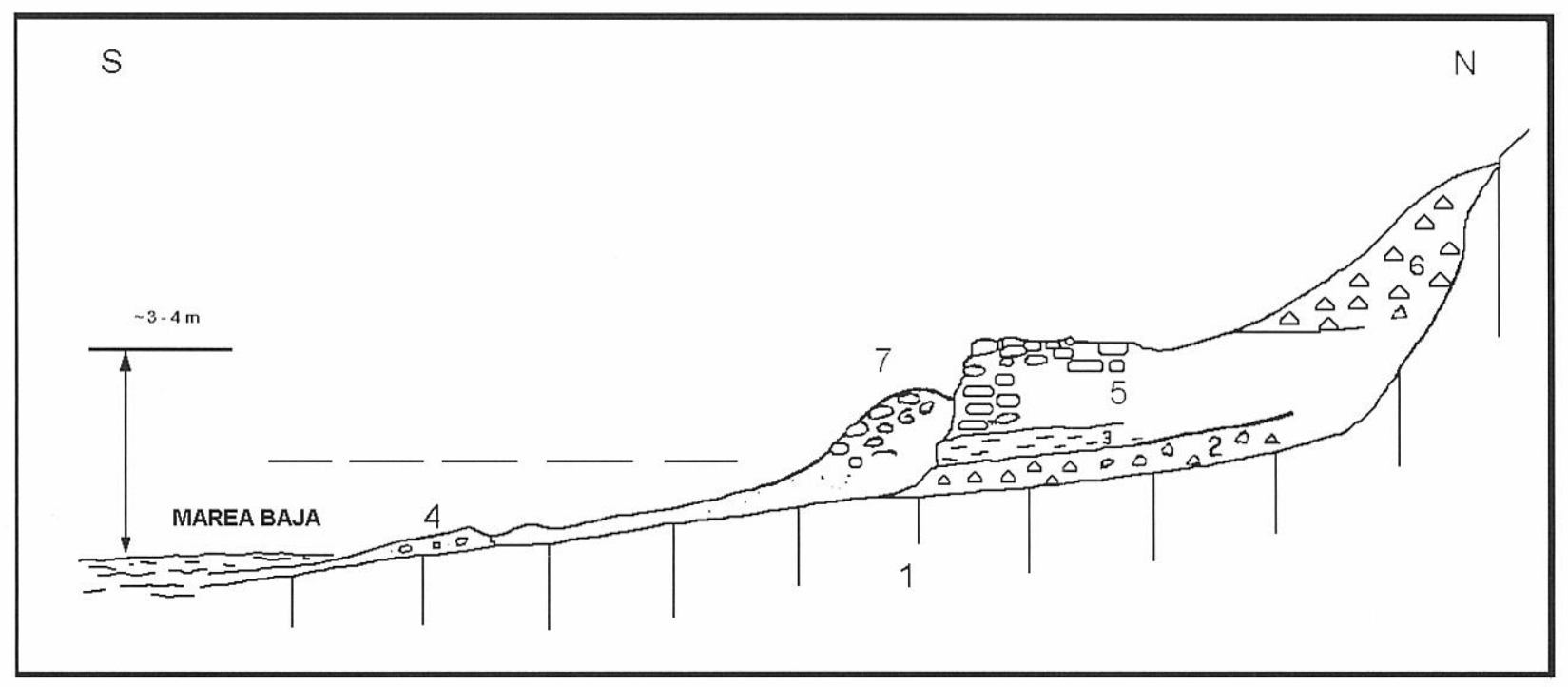

Figura 9. Corte geológico de la La Jaqueta : 1. Serie basáltica antigua. 2. Aluvial, depósito de barranco. 3. Arenas y limos de postplaya. 4. Beach rock erbanense. 5. Berma erbanense. 6. Coluvión. 7. Playa y berma actuales. (Tomado de Meco et al., 1986.)

Geological profile of La Jaqueta: 1. Old basaltic series. 2. Alluvial ravine deposit. 3. Backshore sands and shales. 4. Erbanense beachrock. 5. Erbanense coastal berm. 6. Talus debris (colluvion). 7. Present beach and berm. (Figure taken from Meco et al., 1986.)

extinguida Puffinus holeae (Walker et al., 1990). Las dataciones hechas sobre las cáscaras de huevos encontrados en otras localidades (Bco. de la Barca, situado al sur de Huesos del Caballo) han dado una edad de hace aproximadamente 30.000 años (Walker et al., 1990; Michaux et al., 1991). La existencia de huevos así como de numerosos restos óseos (incluso individuos completos más o menos articulados) de esta especie, tanto en Huesos del Caballo como en las localidades circundantes, sugieren que esta zona constituía una colonia de cría. La alta proliferación de Puffinus holeae ha sido interpretada en relación con un incremento del fenómeno denominado "up-welling" (afloramiento) durante el último periodo glacial, que produciría un aumento de los recursos alimenticios de esta especie. Los cambios climáticos asociados al Presente Interglacial serían, por tanto, una de las posibles causas de la extinción de esta ave, la de mayor tamaño del género (Rognon et al., 1989).

En esta misma formación dunar también se han hallado restos del pigargo Haliaeetus sp. (Rando, 1995), que también está presente en la Cueva del Llano. En este yacimiento también se ha encontrado el múrido Malpaisomys insularis, y las especies de reptiles Gallotia atlantica, Chalcides simonyi y Tarentola angustimentalis.

\section{Parada 5: Tubo volcánico. Cueva del Llano}

La Cueva del Llano es un tubo volcánico situado a unos $2 \mathrm{~km}$ al norte de la población de Villaverde. Es el tubo de mayor longitud de la isla de Fuerteventura y consiste en una galería no ramificada de sección semielíptica, con un recorrido accesible de 453 m (Montserrat y Romero, 1980; Coello et al., 1999).
Las paredes del tubo las constituyen lavas de basaltos alcalinos superficiales, cubiertas por suelos poco potentes del orden aridisoles, de textura limoso-arenosa y con una costra caliza (Torres, 1995). Es posible que las lavas que forman el tubo procedan de Montaña Negra, un cono volcánico de escorias perteneciente a la Serie III de edad Pleistoceno superior (polaridad Brunhes; Fúster y Carracedo, 1979; Coello et al., 1992).

La entrada a la cueva se hace por un derrumbe natural del techo (jameo) situado cerca de su extremo superior, que divide al tubo en dos tramos. El más pequeño $(25 \mathrm{~m}$ visibles), denominado Ramal Nuevo, tiene una altura variable entre 1,5 a $3 \mathrm{~m}$, y una anchura media de $2 \mathrm{~m}$. Esta parte del tubo se halla prácticamente colmatada de sedimentos no consolidados, donde se localizan varios niveles fosilíferos que incluyen abundantes restos de especies de gasterópodos terrestres, micromamíferos, reptiles y aves, la mayor parte de ellas endémicas del archipiélago.

Si se accede al interior del Ramal Nuevo se puede observar en detalle la estratigrafía del yacimiento, donde se han diferenciado tres zonas según las características de su relleno sedimentario: el extremo superior, la zona media y el sector anexo a la entrada.

En dicho relleno, se han distinguido cinco fases de depósito (Fig. 11). La primera fase de relleno corresponde a la sedimentación del lapilli basáltico fino de la unidad CLL1, que sólo se observa en el extremo superior. La segunda fase comprende dos unidades, CLL2 y CLL3; se trata de materiales finamente laminados predominantemente de grano fino con algunos niveles brechoides en la unidad inferior. Estas se observan bien en el tramo medio del tubo. La tercera etapa está representada por la sedimentación de las brechas de las unidades CLL4, CLL5 y CLL6, y sólo se 


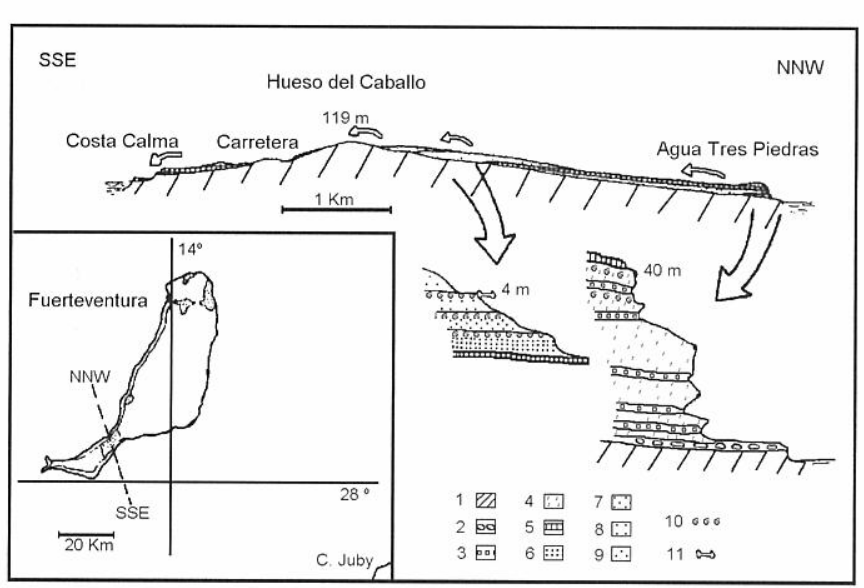

Figura 10. Corte geológico NNO-SSE de Jandía oriental con detalle de las dunas pliocenas (corte de Agua Tres Piedras) y de las dunas pleistocenas (corte de Hueso del Caballo). 1.Basaltos miocenos. 2. Depósitos marinos del tránsito mio-plioceno. 3. Calcarenitas pliocenas con hiladas de aluviones. 4. Duna gris cementada. 5. Costrón calcáreo. 6. Duna gris pleistocena 7. Duna ocre pleistocena. 8. Duna amarilla pleistocena. 9. Suelos deflactados del Holoceno inferior y arenas móviles actuales. 10. Paleosuelos con nidos de himenópteros y gasterópodos terrestres. 11. Osario de pardelas. (Tomado de Meco et al., 1993.)

NNW-SSE geological profile of eastern Jandia with details of Pliocene (Agua Tres Piedras) and Pleistocene dunes (Hueso del Caballo). 1. Miocene basalts. 2. Mio-Pliocene marine transit deposits. 3. Pliocene calcarenites with alluvial lines. 4. Grey cement dune. 5. Calcareous crust. 6. Grey Pleistocene dune. 7. Pleistocene ochre dune. 8. Pleistocene yellow dune. 9. Lower Holocene deflected soils and present mobile sands. 10. Paleosols with Hymenoptera nests and terrestrial gastropods. 11. Shearwaters fossil bones.

encuentran en el extremo superior del tubo. La fase cuarta la forman los limos arcillosos marrones oscuros y finamente laminados de la unidad CLL7. Por último se produce el depósito de las brechas rojizas con clastos fuertemente calcificados que forman las unidades CLL8 y CLL9. Las tres últimas unidades sólo aparecen en el sector anexo a la boca del tubo.

La interpretación paleoambiental (Coello et al., 1999) muestra que durante la fase primera, en el exterior del tubo, podría haber un campo de lavas basálticas cubiertas por depósitos piroclásticos no alterados a suelos. En el interior del tubo, durante esta fase, se van a depositar las cenizas que penetrarán a través de las fisuras de paredes y techo de la cavidad, que en ese momento debía estar cerrada. La fase 2, que ha sido datada en hace $16.900 \pm 900$ años, se produjo bajo un clima húmedo, como muestra la alteración de los piroclastos a suelos, lo que indicaría la existencia de una cobertura vegetal bien desarrollada. En esta época se pudo producir la apertura incipiente del tramo superior del Ramal Nuevo. El relleno, en esta fase, se compone de materiales finos depositados por corrientes de baja energía, siendo frecuentes las inundaciones de la cavidad. La fase 3 se produjo en un clima árido; en la cavidad se producían grandes derrumbes y la colmatación del tramo superior. Los materiales que se depositan en esta fase son gruesos y ligados a episodios torrenciales. En el exterior del tubo se produciría la calcificación y la erosión del suelo en estos periodos torrenciales. La fase 4 , datada de hace $9.340 \pm 370$ años, también se produce en un clima húmedo, de modo que la sedimentación se caracteriza por la existencia de materiales finos, que son depositados por corrientes de baja energía. La fase 5 es similar a la fase 3 . En este periodo se produce la apertura de la boca actual por derrumbes, la sedimentación de materiales gruesos a través de la nueva boca y la colmatación del Ramal Nuevo.

Los restos fósiles se localizan en todas las áreas del relleno, pero son más abundantes en el sector de la entrada y en el extremo superior. Desde el exterior, hasta hace poco tiempo, se podía observar la estratificación del sector anexo a la boca donde se han distinguido tres unidades sedimentarias (CLL7, CLL8 y CLL9) que se disponen sobre la unidad 3 (CLL3) de la zona central y superior. Sin embargo, la acción de las ratas, en primer lugar, a través de la abertura de túneles y en segundo lugar de los expoliadores, han eliminado esta parte del yacimiento por lo que se dificulta su visión. En estas unidades se diferencian hasta ocho niveles fosilíferos. Es interesante destacar la asociación de los múridos Mus musculus y Malpaisomys insularis en los niveles superiores del relleno (CLL9-1 y CLL9-2), mientras que en los restantes sólo se encuentra la segunda especie. También es importante señalar la abundancia de restos de la codorniz Coturnix gomerae, que sólo se había descrito en las islas occidentales, y el hallazgo accidental de un resto perteneciente al género Haliaeetus, un ave marina de gran envergadura.

Martín González et al. (1998b) y Castillo et al. (2001) han realizado un estudio tafonómico de los restos esqueléticos de los micromamíferos, reptiles y aves de las unidades CLL7, CLL8 y CLL9. Los resultados de las abundancias relativas de los elementos esqueléticos de micromamíferos son similares a los obtenidos en egagrópilas de la lechuza común (Tyto alba) en diferentes localidades estudiadas por Andrews (1990). Esto sugiere que esta ave es el principal agente implicado en la formación de la parte del depósito situado en las proximidades de la entrada del tubo. Algunas de las características tafonómicas estudiadas, como por ejemplo la abrasión moderada debida a los procesos digestivos del depredador, concuerdan también con los patrones de este depredador. Sin embargo, los datos de fragmentación no son del todo concordantes con los existentes para Tyto alba, lo que puede deberse a procesos deposicionales.

El estudio paleoecológico de este depósito pone de manifiesto que a lo largo del Cuaternario superior se ha producido un cambio en la dieta de la lechuza común, como muestran las variaciones de la biomasa aportada 


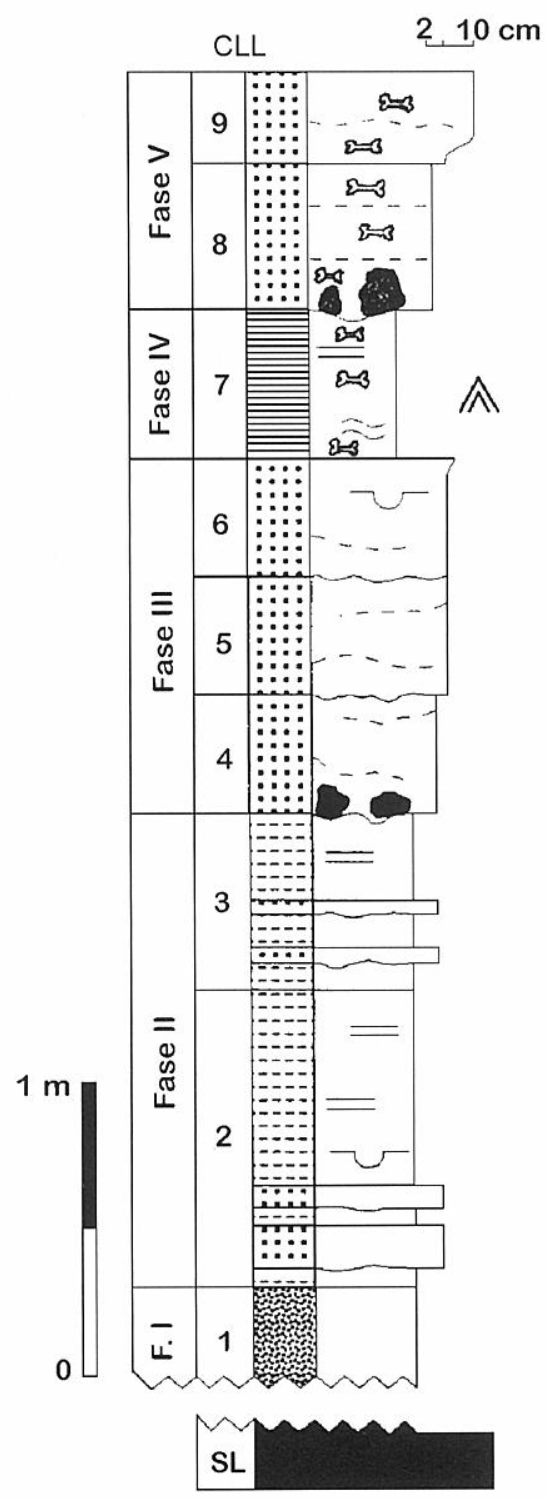

\begin{tabular}{|c|c|c|c|}
\hline (:::::: & Gravas/Brechas & $\approx$ & Laminación ondulada \\
\hline & Limos arenosos & & Bandeado difuso \\
\hline & Arcillas & & "Scour and fill" \\
\hline & Lapilli y cenizas & & Bloques no incrustados \\
\hline & Laminación planar & & Eflorescencias de sulfato \\
\hline
\end{tabular}

Figura 11. Columna estratigráfica del relleno sedimentario de la Cueva del Llano (modificado de Coello et al., 1999).

Stratigraphic column of the volcanic tunnel filling of the Cueva del Llano (modified from Coello et al., 1999).

por las diferentes presas. En los niveles inferiores (CLL81, CLL8-2, CLL8-3), la mayor parte de la biomasa es aportada por Malpaisomys insularis, y en menor proporción están representados las aves y los reptiles. En cambio, en los niveles superiores (CLL9-1, CLL9-2), donde Mus musculus es muy abundante y Malpaisomys insularis está en muy pequeña proporción, se produce un aumento relativo de la biomasa aportada por los reptiles y las aves.

Por otra parte, la ausencia de Coturnix gomerae y el declive de Malpaisomys insularis en los niveles superiores, podrían estar relacionados con un cambio climático hacia condiciones más áridas en el Holoceno. Si bien, en el caso de $M$. insularis, su práctica desaparición en niveles equivalentes en el tubo volcánico de La Cueva de Villaverde ha sido interpretada como reflejo de la introducción de $M$. musculus, asociado a la llegada de los primeros pobladores de Fuerteventura (Boye et al., 1992).

En otro orden de cosas, la riqueza faunística y su conservación, así como su complejidad estratigráfica hacen de este yacimiento uno de los más importantes de Fuerteventura, en particular, y de Canarias, en general. Por lo que es necesario tomar medidas de protección inmediatas.

Por último, en esta parada accederemos al Ramal Inferior, la porción más grande del tubo. En este tramo, la estratigrafía de la Cueva del Llano no ha sido examinada en detalle, pero muestra algunas diferencias con el Ramal Nuevo, como es la reducción drástica de la potencia de los depósitos ( $1 \mathrm{~m}$ a $30 \mathrm{~cm}$ ), y en el número y naturaleza de las unidades sedimentarias representadas.

\section{SÍNTESIS DE LA FORMACIÓN DE LA ISLA OCEÁNICA DE FUERTEVENTURA}

La secuencia de acontecimientos acaecidos en el pasado y que dieron lugar al nacimiento y conformaron la isla de Fuerteventura, tal y como hoy la conocemos, la podemos resumir como sigue.

Entre los $75 \mathrm{Ma}$ y los $40 \mathrm{Ma}$ (la edad concreta todavía no ha podido ser determinada con precisión) en un sector determinado del Atlántico Central, los materiales sedimentarios depositados en el fondo oceánico y su sustrato ígneo (basaltos MORB) sufrieron una importante deformación y posiblemente levantamiento, según algunos autores (Boutin, 1994), e incluso llegaron a emerger sobre la superficie del océano. Sobre estos sedimentos, en condiciones subacuáticas, comienzan a acumularse rocas volcánicas surgidas en erupciones volcánicas provocadas por el ascenso del magma desde el manto terrestre. Este proceso continúa durante un largo período de tiempo comenzándose a formar un importante edificio volcánico submarino.

En las partes más profundas de este edificio comienzan a hacer intrusión magmas de composición piroxenítica, gabroica y sienítica, formando diversos plutones y un importante haz filoniano. Hacia los $30 \mathrm{Ma}$, el edificio volcánico submarino en el cual aparecieron algunas comunidades arrecifales comenzó a emerger sobre la superficie marina.

Esta emersión parece que estuvo acompañada por la intrusión de magmas sienítico-carbonatíticos provocada por la actuación de importantes fallas normales y transcurrentes que dan lugar a la formación de diferentes bloques insulares 
que sufren una etapa de intensa erosión y desmantelamiento (Fernandez et al., 1997).

La actividad volcánica continuó y se formaron tres grandes volcanes en escudo, cuyo diámetro aproximado estaría en torno a los $25-45 \mathrm{~km}$ con una altura de unos 1.600-3.000 m, cuyos centros estarían situados: a) El Meridional, al oeste de la pared de Jandía, b) El Central, entre Pájara y Toto, c) el septentrional, al este del puertito de Los Molinos. Durante las primeras fases de construcción de estos edificios, se produce la intrusión en profundidad de magmas de diversa composición que darán lugar a las rocas plutónicas de la serie gabroide-piroxenítica y a los complejos circulares (Hernández-Pacheco, 1973). Durante esta fase volcánica, la actividad tectónica continúa episódicamente con procesos de levantamiento y hundimiento diferencial de bloques. Estos edificios volcánicos sufrirían con posterioridad una intensa actividad erosiva de desmantelamiento, generándose así los cuchillos y barrancos de los sectores de Jandía y parte oriental de la Isla.

Hace unos $5 \mathrm{Ma}$ se reanuda la actividad volcánica en la Isla y se forman algunos pequeños edificios e importantes coladas que rellenan parcialmente algunos de los barrancos previamente formados. Esta actividad ha sido más o menos constante hasta la actualidad. Las últimas manifestaciones las podemos situar en 1915, ya que en ese año fueron frecuentes los terremotos en el valle de Pájara y se produjo una importante actividad fumaroliana, reflejo todo ello de una erupción abortada.

\section{AGRADECIMIENTOS}

Los autores agradecen la inestimable colaboración de D. Ignacio Hernández de la Unidad de Patrimonio del Cabildo Insular de Fuerteventura, y a todo el personal que hizo posible la excursión de las XIV Jornadas de Paleontología a la Isla de Fuerteventura. Este trabajo ha sido financiado por el Area de Cultura del Cabildo de Fuerteventura y la Subdirección General de Formación, Perfecionamiento y Movilidad de Investigadores del MEC.

\section{BIBLIOGRAFÍA}

Ahijado, A. y Hernández-Pacheco, A. 1990. Las rocas ultramáficas alcalinas del Jable de Salinas, Fuerteventura, Islas Canarias. Revista de la Sociedad Geológica de España, 3, 275-287.

Ahijado, A. y Hernández-Pacheco, A. 1992. El complejo ultramáfico-carbonatítico del Macizo de Amanay, Fuerteventura, Islas Canarias. Actas del III Congreso Geológico de España y VIII Congreso Latinoamericano de Geología, Salamanca, 1, 315-318.

Ahijado, A., Hernández-Pacheco, A. y Mata, J. 1992. Características geoquímicas de las carbonatitas de la Punta del Peñón Blanco. Fuerteventura. Canarias. Geogaceta, 11, 120-122.

Ancochea, E., Brandle, J.L., Cubas, C. R., Hernán, F. y Huertas, M. J. 1993. La Serie I de la Isla de
Fuerteventura. Memoria de la Real Academia de Ciencias Experimentales Fİsicas y Naturales, Serie de Ciencias Naturales, 27, 151 pp.

Ancochea, E., Brändle, J.L., Cubas, C.R., Hernán, F. and Huertas, M.J. 1996. Volcanic complexes in the eastern ridge of the Canary Islands: the Miocene activity of the island of Fuerteventura. Journal of Volcanology and Geothermal Research, 70, 183-204.

Anderson, D. L., Tanimoto, T. and Zhang, Y. 1992. Plate tectonics and hotspots: the third dimension. Science, 256, 1645-1651

Andrews, P. 1990. Owls, Caves and Fossils. Natural History Museum Publications, London, 231.

Balcells, R., Barrera, J.L., Gómez, J.A., Cueto, L.A., Ancochea, E., Huertas, M. J., Ibarrola, E. y Snelling, N. 1994. Edades radiométricas en la Serie Miocena de Fuerteventura. (Islas Canarias). Boletín Geológico y Minero, 35, 450-470.

Banda, E., Surinach, E., Udias, A., Dañobeitia, J.J., Mueller, S. T., Mezcua, J., Boloix, M., Ortiz, R. and Correig, A. 1980. Explosion seismology study of the Canary Islandsfirst results. Abstracts. 7th EGS-ESC Meeting. Budapest, 5 pp.

Banda, E., Dañobeitia, J.J., Surinach, E. and Ansorge, J. 1981. Features of crustal structure under the Canary Islands. Earth and Planetary Sciences Letters, 55, 11-24.

Barrera, J.L., Fernández Santín, S., Fúster, J.M. e Ibarrola, E. 1986. Ijolitas-Sienitas-Carbonatitas de los Macizos del Norte de Fuerteventura. Boletín Geológico y Minero, 92, 309-321.

Bosshard, E. and Macfarlane, D. J. 1970. Crustal structure of the Western Canary Islands from seismic refraction and gravity data. Journal of Geophysical Research, 75, 4901-4918.

Boutin, C. 1994. Stygobiology and historical Geology: The age of Fuerteventura (Canary Islands), as inferred from its presents stygofauna. Bulletin de la Societé Geologique de France, 165, 273-285.

Boye, P., Hutterer, R., López-Martínez, N and Michaux, J. 1992. A reconstruction of the Lava mouse (Malpaisomys insularis), an extinct rodent of the Canary Islands. Zeitschrift für Säugetierkunde, 57, 29-38.

Cantagrel, J.M., Fúster, J.M., Pin, C., Renaud, U. et Ibarrola, E. 1993. Age Miocène inférieur des carbonatites de Fuerteventura. Comptes Rendus de l'Academie des Sciences de Paris, 316, 1147-1153.

Caress, D. W., Mcnutt, M. R., Detrick, R. S. and Mutter, J. C. 1995. Seismic imaging of hotspot-related crustal underplating beneath the Marquesas Islands. Nature, 373, 600-603.

Carlisle, D. 1963. Pillow breccias and their aquagene tuffs, Quadra Island, British Columbia. Journal of Geology, 71, 48-71.

Carracedo, J. C. 1984. El Origen de las Islas. Capítulo V. In: Geografía de Canarias. Tomo I. Ed. Interinsular Canaria, 56-64.

Carrascosa, M.C. and López-Martínez, N. 1988. The house mouse from a prehistoric site in Fuerteventura (Canary Islands, Spain). Bonner zoologische Beiträge, 39, 237 256. 
Casillas, R., Ahijado, A. y Hernández-Pacheco, A. 1994. Zonas de cizalla dúctil en el complejo basal de Fuerteventura. Geogaceta, 15, 65-69.

Castillo, C., Coello, J.J., Martín Oval, M., González Hernández, R., Estévez, A. y Meneses, M.D. 1996a. Tafonomía de las concentraciones óseas de vertebrados en los tubos volcánicos de Canarias: implicaciones paleoecológicas. In: II Reunión de Tafonomía y Fosilización (Eds. G. Mélendez Hevia, M.F. Blasco Sancho e I. Pérez Urresti). Institución "Fernando El Católico" (C.S.I.C.), Zaragoza, 89-96.

Castillo, C., López, M., Martín, M. y Rando, J. C. 1996b. La Paleontología de vertebrados en Canarias. Revista Española de Paleontología, $\mathbf{n}^{\mathbf{a}}$ extraordinario, 237-247.

Castillo, C., Castillo, J, Coello, J.J., Martín, E., Martín, M. y Méndez, A. 1999. La tutela del patrimonio paleontológico en Canarias. Valoración general. Coloquios de Paleontologİa, 50, 11-23.

Castillo, C., Martín González, E. and Coello, J.J. 2001. Small vertebrate taphonomy of La Cueva del Llano, a volcanic cave on Fuerteventura (Canary Islands, Spain). Palaeoecological implications. Palaeogeography, Palaeoclimatology, Palaeoecology, 166, 277-291.

Cendrero, A. 1966. Los volcanes recientes de Fuerteventura (Islas Canarias). Estudios Geológicos, 22, 201-226.

Coello, J., Cantagrel, J.M., Hernán, F., Fúster, J.M., Ibarrola, E., Ancochea, E., Casquet, C., Jamond, C., Díaz de Terán, J. R. and Cendrero, A. 1992. Evolution of the Eastern Volcanic Rigde of the Canary Islands Based on New K-Ar Data. Journal of Volcanology and Geothermal Research, 53, 251-274.

Coello, J.J., Castillo, C. and Martín González, E. 1999. Stratigraphy, chronology and paleoenvironmental reconstruction of the Quaternary sedimentary infilling of a volcanic tube in Fuerteventura, Canary Islands. Quaternary Research, 52, 360-368.

Criado, C. 1991. La evolución del relieve de Fuerteventura. Servicio de Publicaciones del Excmo. Cabildo Insular de Fuerteventura. Puerto del Rosario. 318 pp.

Cubas, C.R., Fernández Santín, S., Hernán, F., HernándezPacheco, A. y de la Nuez, J. 1989. Los domos sálicos de Fuerteventura. Revista de Materiales y Procesos Geológicos, 6, 71-97.

Ellis, W.N. and Ellis-Adam, A.C. 1993. Fossil brood cells of solitary bees on Fuerteventura and Lanzarote, Canary Islands (Hymenoptera: Apoidea). Entomologische Bereicht, Amsterdam, 53, 161-173.

Fernández, C., Casillas, R., Ahijado, A., Perelló, V. and Hernández-Pacheco, A. 1997. Shear zones as a result of intraplate tectonics in oceanic crust $\uparrow$ : the example of the Basal Complex of Fuerteventura (Canary Islands). Journal of Structural Geology, 19, 41-57.

Fúster, J. M. y Aguilar, M. 1965. Nota previa sobre la Geología del Macizo de Betancuria. Fuerteventura (Islas Canarias). Estudios Geológicos, 21, 181-197.

Fúster, J.M. and Carracedo, J.C. 1979. Magnetic polarity mapping of Quaternary volcanic activity of Fuerteventura and Lanzarote (Canary Islands). Estudios Geológicos, 35, 59-66.

Fúster, J.M., Cendrero, A., Gastesi, P., Ibarrola, E. y López
Ruiz, J. 1968a. Geología y volcanología de las Islas Canarias. Fuerteventura. Instituto "Lucas Mallada". Consejo Superior de Investigaciones Científicas, Madrid. $239 \mathrm{pp}$.

Fúster, J. M., Agostini, L., Aguilar, M., Bravo, T., Castañón, A., Cendrero, A., Hernández-Pacheco, A., López-Ruiz, J. y Sánchez-Cela, V. 1968b. Mapa Geológico de España 1:50.000. La Oliva. Instituto Geológico y Minero de España.

Fúster, J.M., Muñoz, M., Sagredo, J., Yébenes, A., Bravo, T. y Hernández-Pacheco, A. 1980. Excursión nº 121 A + C del $26^{\circ}$ I.G.C. a las Islas Canarias. Boletín del Instituto Geológico y Minero de España, 92, 351-390.

Fúster, J.M., Barrera, J.L., Muñoz, M., Sagredo, J. y Yébenes, A. 1984a. Mapa y Memoria explicativa de la Hoja de Pájara del Mapa Geológico Nacional a escala 1:25.000. IGME, $63 \mathrm{pp}$.

Fúster, J.M., Yébenes, A., Barrera, J.L., Muñoz, M. y Sagredo, J. 1984b. Mapa y Memoria explicativa de la Hoja de Betancuria del Mapa Geológico Nacional a escala 1:25.000. IGME, $34 \mathrm{pp}$.

Garralda, M. D., Hernández, F. y Sánchez, D. 1981. El enterramiento de la cueva de Villaverde (La Oliva, Fuerteventura). Anuario de Estudios Atlánticos, 27, 673690.

Gastesi, P. 1969a. El Complejo básico y ultrabásico de Betancuria, Fuerteventura (Islas Canarias): estudio petrológico. Estudios Geológicos, 25, 1-51.

Gastesi, P. 1969b. Petrology of the ultramafic and basic rocks of Betancuria massif, Fuerteventura Island ( Canarian Archipelago ). Bulletin of Volcanology, 33, 1008-1038.

Gastesi, P. 1973. Is the Betancuria massif of Fuerteventura Island, Canary Islands, a uplifted piece of oceanic crust? Nature Physical Science, 246 (155), 102-104.

Hernández-Pacheco, A. 1973. Sobre el significado de las rocas granudas gabroides de los complejos basales de Fuerteventura, La Palma y La Gomera. Estudios Geológicos, 29, 549-577.

Hernández-Pacheco, A. 1989. Datos sobre la geología y petrología del Macizo de Amanay, Fuerteventura, Canarias. Geogaceta, 6, 40-43.

Hoernle, K. and Tilton, G. R. 1991. Sr-Nd-Pb isotope data for Fuerteventura basal complex and subaerial volcanics: application to magma genesis. Schweizerische Mineralogische. Petrographische Mitteilungen, 71, 5-21.

Holik, J. S., Rabinowitz, P. D. and Austin, J. A. 1991. Effects of Canary hotspot volcanism on structure of oceanic crust off Morocco. Journal of Geophysical Research, 96(B7), 12039-12067.

Hutterer, R. 1989. Recent and fossil slugs of the genus Parmacella in the Canary Islands, with the description of three new species (Pulmonata: Parmacellidae). Archiv für Molluskenkunde, 120, 73-93.

Hutterer, R. 1990. A new canarian theba (Gastropoda: Helicilae) with african affinities. Schriften zur Malakozoologie, 3, 1-6.

Hutterer, R., López-Martínez, N. and Michaux, J. 1988. A new rodent from Quaternary deposits of the Canary Islands and its relationships with neogene and recent 
murids of Europe and Africa. Paleovertebrata, 18, 241262.

Hutterer, R., Maddalena, T. and Molina, O.M. 1992. Origin and evolution of the endemic Canary Island shrews (Mammalia: Soricidae). Biological Journal of the Linnean Society, 46, 49-58.

Hutterer, R., López-Jurado, L.F. and Vogel, P. 1987. The shrews of the eastern Canary Islands: a new species (Mammalia: Soricidae). Journal of Natural History, 21, 1347-1357.

Hutterer, R., García Talavera, F., López Martínez, N. and Michaux, J. 1997. New chelonian eggs from the Tertiary of Lanzarote and Fuerteventura, and a review of fossil tortoises of the Canary Islands (Reptilia, testudinidae). Vieraea, 26, 139-161.

Ibarrola, E., Fúster, J.M. and Cantagrel, J. M. 1989. Edades $\mathrm{K}-\mathrm{Ar}$ de las rocas volcánicas submarinas en el sector norte del Complejo Basal de Fuerteventura. ESF Meeting on Canarian Volcanism. Lanzarote, 124-128.

Jenkyns, H.C. 1980. Cretaceous anoxic events †; from continents to oceans. Journal of the Geological Society of London, 137, 171-188.

Le Bas, M. J. 1981. The pyroxenite-ijolite-carbonatite intrusive igneous complexes of Fuerteventura, Canary Islands. Journal of the Geological Society of London, 138, 496.

Le Bas, M.J. Rex, D.C. and Stillman, C.J. 1986. The early magmatic chronology of Fuerteventura. Geological Magazine, 123, 287-298.

López Ruiz, L. 1970. Estudio petrográfico y geoquímico del Complejo filoniano de Fuerteventura (Islas Canarias). Estudios Geológicos, 26, 173-208.

Mangas, J., Pérez Torrado, F.J., Reguillón, R.M. y Cabrera, M.C. 1992. Prospección radiométrica en rocas alcalinas y carbonatitas de la serie plutónica I de Fuerteventura (Islas Canarias). Resultados preliminares e implicaciones metalogénicas. Actas del III Congreso Geológico de España y VIII Congreso Latinoamericano de Geología. Salamanca, 3, 389-393.

Mangas, J., Pérez Torrado, F.J., Reguillón, R.M. and MartínIzard, A. 1993. Alkaline and carbonatitic intrusive complexes from Fuerteventura (Canary Islands): radiometric exploration, chemical composition and stable isotope. In: Int. Conf. Rare Earth Minerals: chemistry, origin and ore deposits. London, 79-81.

Mangas, J., Pérez Torrado, F.J., Reguillón, R.M. y MartínIzard, A. 1994. Mineralizaciones de tierras raras ligadas a los complejos intrusivos alcalino-carbonatíticos de Fuerteventura (Islas Canarias). Boletín de la Sociedad Española de Mineralogía, 17, 212-213.

Martín González, E., Castillo, C., Gutiérrez González, M. y Aguirre, J. 1998a. Modelo sedimentario, composición fosilífera y tafonomía de los depósitos litorales someros del Plioceno inferior de Fuerteventura (Islas Canarias). In: XIV Jornadas de Paleontología, La Laguna (Eds. C. Castillo y M. Martín Oval). 117-120.

Martín González, E., Castillo, C. y Coello, J.J. 1998b. Tafonomía y paleoecología de los microvertebrados de la Cueva del Llano (Fuerteventura, Islas Canarias). In: XIV Jornadas de Paleontologİa, La Laguna (Eds. C. Castillo y M. Martín Oval), 113-116.

McMinn, M., Jaume, D. i Alcover, J.A. 1990. Puffinus olsoni n. sp.: nova espècie de baldritja recentment extingida provinent de dèposits espeleològics de Fuerteventura i Lanzarote (Illes Canàries, Atlantic Oriental). Endins, 16, 63-71.

Meco, J. 1975. Los niveles con Strombus de Jandía (Fuerteventura, Islas Canarias). Anuario de Estudios Atlánticos, 21, 643-660.

Meco, J. 1977. Paleontología de Canarias I: los Strombus neógenos y cuaternarios del Atlántico euroafricano (Taxonomía, Bioestratigrafía y Paleoecología). Cabildo Insular de Gran Canaria Ed., Madrid, 142 pp.

Meco, J. 1988. The emergent littoral deposits in Fuerteventura and the evolution of the canarian marine faunas during the Cuaternary. Deserts, Past and future evolution. Fuerteventura 3-6 Jan. 1988 IGCP-252 (Ed. N. Petit Maire), Marsaille, 166-178.

Meco, J. 1992. Los Ovicaprinos de Villaverde. Estudios Prehispánicos. Dirección General de Patrimonio Histórico, 2, 1-167.

Meco, J. 1993. Testimonios paleoclimáticos en Fuerteventura. Tierra y Tecnología, 6, 41-48.

Meco, J. y Petit-Maire, N. 1986. El Cuaternario reciente de Canarias. Le Quaternarie recent des Canaries. Las Palmas-Marsaille. 94 pp.

Meco, J. et Pomel, R. S. 1985. Les formations marines et continentales intervolcaniques des Iles Canaries Orientales (Grande Canarie, Fuerteventura et Lanzarote): stratigraphie et signification paleoclimatique. Estudios Geológicos, 41, 223-227.

Meco, J. and Stearns, Ch. E. 1981. Emergent litoral deposits in the Eastern Canary Islands. Quaternary Research, 15, 199-208.

Meco, J., Hernández, F. y Sánchez, D. 1982. La cueva de Villaverde (Fuerteventura) y su mastologÌa (nota preliminar). Libro homenaje a Jesús Arencibia. Servicio de Publicaciones de la Escuela Universitaria de Formación del Profesorado de E.G.B. de Las Palmas, Las Palmas de Gran Canaria, 187-194.

Meco, J., Pomel, R. S., Aguirre, E. and Stearns, Ch. E. 1987. The recent marine Quaternary of the Canary Islands. Trabajos Neógeno Cuaternario del CSIC, 10, 283-305.

Meco, J., Petit-Maire, N. et Reyss, J.L. 1992. Le Courant des Canaries pendant le stade isotopique 5, d'après la composition faunistique d'un haut niveau marin à Fuerteventura $\left(28^{\circ} \mathrm{N}\right)$. Comptes Rendus de l'Academie des Sciences de Paris, 314, Série 2, 203-208.

Michaux, J., Hutterer, R. and López-Martínez, N. 1991. New fossil faunas from Fuerteventura, Canary Islands: Evidence for a Pleistocene age of endemic rodents and shrews. Comptes Rendus de l'Academie des Sciences de Paris, 312, Série 2, 801-806.

Montlegard, C. 1991. Systematique moleculaire (Immunologie) de quelques Muridae actuels et fossile. These, Universidad Montpellier II, France, 129 pp. (inédita).

Montserrat, A. y Romero, M. 1980. Introducción al conocimiento vulcanoespeleológico de la isla de Fuerteventura (Islas Canarias). Speleon, 26, 93-98. 
Muñoz, M. 1969. Estudio petrológico de las formaciones alcalinas de Fuerteventura (Islas Canarias). Estudios Geológicos, 25, 257-310.

Muñoz, M. y Sagredo, J. 1975. Existencia de metamorfismos superpuestos en el complejo basal de Fuerteventura (Canarias). I Asamblea Nac. Geodesia y Geofísica, 1287-1288.

Muñoz, M. y Sagredo, J. 1989. Características del metamorfismo térmico producido por los eventos plutónicos intrusivos más recientes del Complejo Basal de Fuerteventura. Abst. ESF Meeting on Canarian Volcanism. Lanzarote, 104-108.

Rando, J.C. 1995. Presencia de restos de pigargo (Haliaeetus sp.) (Aves: Accipitridae) en yacimientos paleontológicos de Fuerteventura. Vieraea, 24, 65-69.

Renz, O., Bernoulli, D. and Hottinger, L. 1992. Cretaceous ammonites from Fuerteventura, Canary Islands. Geological Magazine, 129, 763-769.

Robertson, A.H.F. and Bernouilli, D. 1982. Stratigraphy, facies and significance of Late Mesozoic and Early Terciary Sedimentary rocks of Fuerteventura (Canary Islands) and Maio (Cape Verde Islans). In: Geology of the Northwest African Continental Margin. Von Rad, Hiaz Sarnthein and Seibold, 498-525.

Robertson, A. H. F. and Stillman, C.J. 1979a. Late Mesozoic sedimentary rocks of Fuerteventura, Canary Islands. Implications for West Africa continental margin evolution. Journal of the Geological Society of London, 136, 47-60.

Robertson, A. H. F. and Stillman, C.J. 1979b. Submarine volcanic and associated sedimentary rocks of the Fuerteventura Basal Complex, Canary Islands. Geological Magazine, 116, 203-214.

Rognon, P. et Coudé-Gaussen, G. 1987. Reconstitution paléoclimatique à partir des sédiments du Pleistocène supérieur et de l'Holocène du nord de Fuerteventura (Canaries). Zeitschrift für Geomorphologie, N.F, 31 (1), 1-19.

Rognon, P. et Coudé-Gaussen, G. 1992. Reconstitution des circulations atmosphériques du Pleistocène terminal et de l'Holocène au large de l'Afrique entre 15 et $35^{\circ} \mathrm{N}$. In: Palaeoecology of Africa and the surroundings islands (Ed. E.M. van Zinderen Bakker Sr), 1-25.

Rognon, P., Coudé-Gaussen, G., Le Coustumer, M.N., Balouet, J.C. et Occhietti, S. 1989. Le massif dunaire de Jandia (Fuerteventura, Canaries): Èvolution des paléoenvironnements. De 20000 BP à l'actuel. Bulletin de l'Association française pour l'étude du Quaternaire, 1, 31-37.

Rothe, P. 1968. Mesozoische Flysch-Ablagerugen auf der Kanaren insel Fuerteventura. Geologische Rundschau, 58, 314-332

Rothe, P and Klemmer, K. 1991. Fossil eggs of terrestrial tortoises (Family Testudinidae) from Pliocene calcarenites of Fuerteventura (Canary Islands, Spain). Senckenbergiana lethaea, 71, 307-317.
Sagredo, J., Ancochea, E., Brändle, J. L., Cubas, C. R., Fúster, J. M., Hernández-Pacheco, A. y Muñoz, M. 1989. Magmatismo hipoabisal-subvolcánico y vulcanismo en un ámbito geodinámico distensivo (Fuerteventura, Islas Canarias). Abtract of European Science Foundation Meeting on Canarian volcanism. Lanzarote, 100-103.

Schmincke, H.U. 1984. Pyroklastische Gesteine. In: Sedimentgesteine (Ed. H. Füchtbauer). Schweizerbartische Verlagsbuchhandlung, Stuttgart, 720-785.

Seilacher, A., Reif, W.E. and Westfal, F. 1985. Sedimentological, ecological and temporal patterns of fossil Lagerstäten. Philosophical Transactions of the Royal Society London, B, 311, 5-13.

Staudigel, H. and Schmincke, H.U. 1984. The Pliocene seamount series of La Palma, Canary Islands. Journal of Geophysical Research, 89, 11195-11215.

Steiner, C., Hobson, A., Favre, P., Stampfli, G.M. and Hernández, J. 1998. Early Jurassic sea-floor spreading in the central Atlantic, the Jurassic sequence of Fuerteventura (Canary Islands). Geological Society of America Bulletin, 110,1304 - 1317.

Stillman, C. J. 1987. A Canary Islands Dyke Swarm: Implications for the formation of oceanic islands by extensional fissural volcanism. In: Mafic Dyke Swarms (Ed. H. C. Halls and W. F. Fahrig). Geological Association, Canada, 34-54.

Stillman, C. J. and Robertson, A. H. F. 1977. The dyke swarm of the Fuerteventura Basal Complex, Canary Islands. Abstracts Geological Society London Newsletter, $6,8$.

Stillman, C.J., Fuster, J.M., Bennell-Baker, M.J., Muñoz, M., Smewing, J.D. and Sagredo, J. 1975. Basal Complex of Fuerteventura (Canary Islands) is an oceanic intrusive complex with rift-system affinities. Nature, 257, 469471.

Torres, J.M. 1995. El suelo como recurso natural: procesos de degradación y su incidencia en la desertificación de la isla de Fuerteventura. Tesis Universidad de La Laguna, 300 pp. (inédita).

Walker, C. A., Wragg, G. M. and Harrison, C. J. O. 1990. A new shearwater from the Pleistocene of the Canary Islands and its bearing on the evolution of certain puffinus shearwaters. Historical Biology, 3, 203-224.

Woolley, A.R. and Kempe, D.R.C. 1989. Carbonatites: nomenclature, average chemical compositions, and element distribution. In: Carbonatites. Genesis and evolution (Ed. K. Bell). Unwin Hyman, Londres, 1-37.

Zazo, C., Goy, J.L., Hillarie-Marcel, C.L., Dabrio, C.J., Hoyos, M., Lario, J., Bardají, T., Somoza, L. y Silva, P.G. 1994. Variaciones del nivel del mar: estadios isotópicos 7, 5 y 1 en las costas peninsulares ( $\mathrm{S}$ y $\mathrm{SE}$ ) e insulares españolas. AEQUA Monografías, 2, 26-35.

Zazo, C., Hillarie-Marcel, C.L., Goy, J.L., Ghaleb, B. y Hoyos, M. 1997: Cambios del nivel del mar-clima en los últimos 250 ka: (Canarias Orientales, España). Boletín Geológico y Minero, 108, 31-41. 